\title{
Tissue-specific control of brain-enriched miR-7 biogenesis
}

\author{
Nila Roy Choudhury, ${ }^{1}$ Flavia de Lima Alves, ${ }^{1}$ Luisa de Andrés-Aguayo, ${ }^{2}$ Thomas Graf, ${ }^{2}$ \\ Javier F. Cáceres, ${ }^{3}$ Juri Rappsilber, ${ }^{1,4}$ and Gracjan Michlewski ${ }^{1,5}$ \\ ${ }^{1}$ Wellcome Trust Centre for Cell Biology, University of Edinburgh, Edinburgh EH9 3JR, United Kingdom; ${ }^{2}$ Differentiation \\ and Cancer Program, Center for Genomic Regulation Barcelona, 08003 Barcelona, Spain; ${ }^{3}$ MRC Human Genetics Unit, Institute \\ of Genetics and Molecular Medicine, University of Edinburgh, Western General Hospital, Edinburgh EH4 2XU, United Kingdom; \\ ${ }^{4}$ Department of Biotechnology, Technische Universität Berlin, 13353 Berlin, Germany
}

\begin{abstract}
MicroRNA (miRNA) biogenesis is a highly regulated process in eukaryotic cells. Several mature miRNAs exhibit a tissue-specific pattern of expression without an apparent tissue-specific pattern for their corresponding primary transcripts. This discrepancy is suggestive of post-transcriptional regulation of miRNA abundance. Here, we demonstrate that the brain-enriched expression of miR-7, which is processed from the ubiquitous hnRNP $\mathrm{K}$ pre-mRNA transcript, is achieved by inhibition of its biogenesis in nonbrain cells in both human and mouse systems. Using stable isotope labeling by amino acids in cell culture (SILAC) mass spectrometry combined with RNase-assisted RNA pull-down, we identified Musashi homolog 2 (MSI2) and Hu antigen R (HuR) proteins as inhibitors of miR-7 processing in nonneural cells. This is achieved through HuR-mediated binding of MSI2 to the conserved terminal loop of pri-miR-7. Footprinting and electrophoretic gel mobility shift analysis (EMSA) provide further evidence for a direct interaction between pri-miR-7-1 and the HuR/MSI2 complex, resulting in stabilization of the pri-miR-7-1 structure. We also confirmed the physiological relevance of this inhibitory mechanism in a neuronal differentiation system using human SH-SY5Y cells. Finally, we show elevated levels of miR-7 in selected tissues from MSI2 knockout (KO) mice without apparent changes in the abundance of the pri-miR-7 transcript. Altogether, our data provide the first insight into the regulation of brain-enriched miRNA processing by defined tissue-specific factors.
\end{abstract}

[Keywords: miRNA biogenesis; brain-enriched miRNA; RNP complex; MSI2; HuR]

Supplemental material is available for this article.

Received June 22, 2012; revised version accepted November 27, 2012.

MicroRNAs (miRNAs) constitute a large family of short (21- to 23-nucleotide [nt]), noncoding RNAs that regulate gene expression and control a variety of biological processes, including cell cycle, developmental timing, differentiation, metabolism, neuronal patterning, and aging (Ketting et al. 2001; Lee and Ambros 2001; Shi et al. 2010; Pauli et al. 2011). Given their diverse functions in metazoans, it is not surprising that their spatial and temporal expression is tightly regulated (Bushati and Cohen 2007). Importantly, several miRNAs are expressed in a tissuespecific manner, thereby contributing to cell identity and function (Landgraf et al. 2007).

Mature miRNAs are derived from primary transcripts (pri-miRNAs) by sequential nuclear and cytoplasmic processing events (Zamore and Tomari 2005). In the nucleus,

\footnotetext{
${ }^{5}$ Corresponding author

E-mail gmichlew@staffmail.ed.ac.uk

Article is online at http://www.genesdev.org/cgi/doi/10.1101/gad.199190.112. Freely available online through the Genes \& Development Open Access option.
}

the Microprocessor complex-which contains the RNase III Drosha (Lee et al. 2003) and its RNA-binding partner, DGCR8 (Denli et al. 2004; Gregory et al. 2004; Han et al. 2004; Landthaler et al. 2004)_-generates stem-loop precursors (pre-miRNAs) that are exported to the cytoplasm by Exportin 5 (for review, see Kim 2004). In the cytoplasm, the RNase III enzyme Dicer cleaves off the pre-miRNA terminal loop (TL), leaving a miRNA duplex (Hutvagner et al. 2001; Ketting et al. 2001). Subsequently, one strand of this duplex is incorporated into the RNA-induced silencing complex (RISC), which targets specific mRNAs and controls their expression by affecting either transcript stability or translation (Hammond et al. 2000; Eulalio et al. 2009; Fabian et al. 2010). Recently, it has become clear that the miRNA biogenesis pathway is subjected to regulation by a variety of protein factors. We showed previously that hnRNP A1, a protein implicated in many aspects of RNA processing, binds to the conserved TL (CTL) of pri-miR-18a (Guil and Caceres 2007; Michlewski et al. 2008) and pri-let-7a-1 (Michlewski and Caceres 2010a), stimulating and inhibiting their processing, respectively. 
Furthermore, we identified several other pri-miRNAs with highly conserved TLs and hypothesized that this may reflect their requirement for auxiliary factors to regulate their processing (Michlewski et al. 2008).

miRNA-7 resides within intron 15 of a very abundant and ubiquitously expressed pre-mRNA that encodes the hnRNP K protein (Yanai et al. 2005). Interestingly, its precursor, pri-miR-7-1, harbors a highly conserved TL. Surprisingly, in humans, miR-7 itself is enriched in brain and pancreatic tissues despite the ubiquitous expression of its host hnRNP K pre-mRNA (Landgraf et al. 2007; Hsu et al. 2008). This discrepancy suggests that miR-7 expression is regulated at the post-transcriptional level. Here, using miRNA in vitro processing assays, we show that pri-miR-7-1 processing is inhibited in nonneural cells by the binding of trans-acting factors to its CTL. Stable isotope labeling by amino acids in cell culture (SILAC) (Ong et al. 2002) has been previously demonstrated to reveal proteins that bind specifically to phosphorylation sites (Schulze and Mann 2004), epigenetic marks (Vermeulen et al. 2010), and functional DNA elements (Mittler et al. 2009). Using SILAC mass spectrometry combined with RNase-assisted RNA pull-down, we demonstrate that the biogenesis of brain-enriched miR-7 is inhibited by the Musashi homolog 2
(MSI2) and $\mathrm{Hu}$ antigen $\mathrm{R}$ (HuR) proteins, which act through converging pathways in nonneural cells. We reveal that MSI2 and HuR are interacting partners and provide evidence that the role of HuR is to assist MSI2 binding, which is the actual factor that inhibits miR-7 biogenesis. We also show that upon HuR and MSI2 binding to pri-miR-7-1, its stem structure becomes more rigid, suggesting a potential mechanism of inhibition of Microprocessor cleavage. We confirm the physiological relevance of MSI2/HuR-mediated inhibition of miR-7 biogenesis in a neuronal differentiation model of human neuroblastoma SH-SY5Y cells. Finally, we show elevated levels of miR-7 but not pri-miR-7 in selected tissues of MSI2 knockout (KO) mice. Altogether, these results provide the first example of tissue-specific control of brainenriched miRNA maturation by defined factors.

\section{Results}

The biogenesis of brain-enriched miR-7 is regulated post-transcriptionally

miR-7 resides on intron 15 of the hnRNP K pre-mRNA (Fig. 1A). According to the gene expression database GeneNote, hnRNP K pre-mRNA is ubiquitously expressed in all
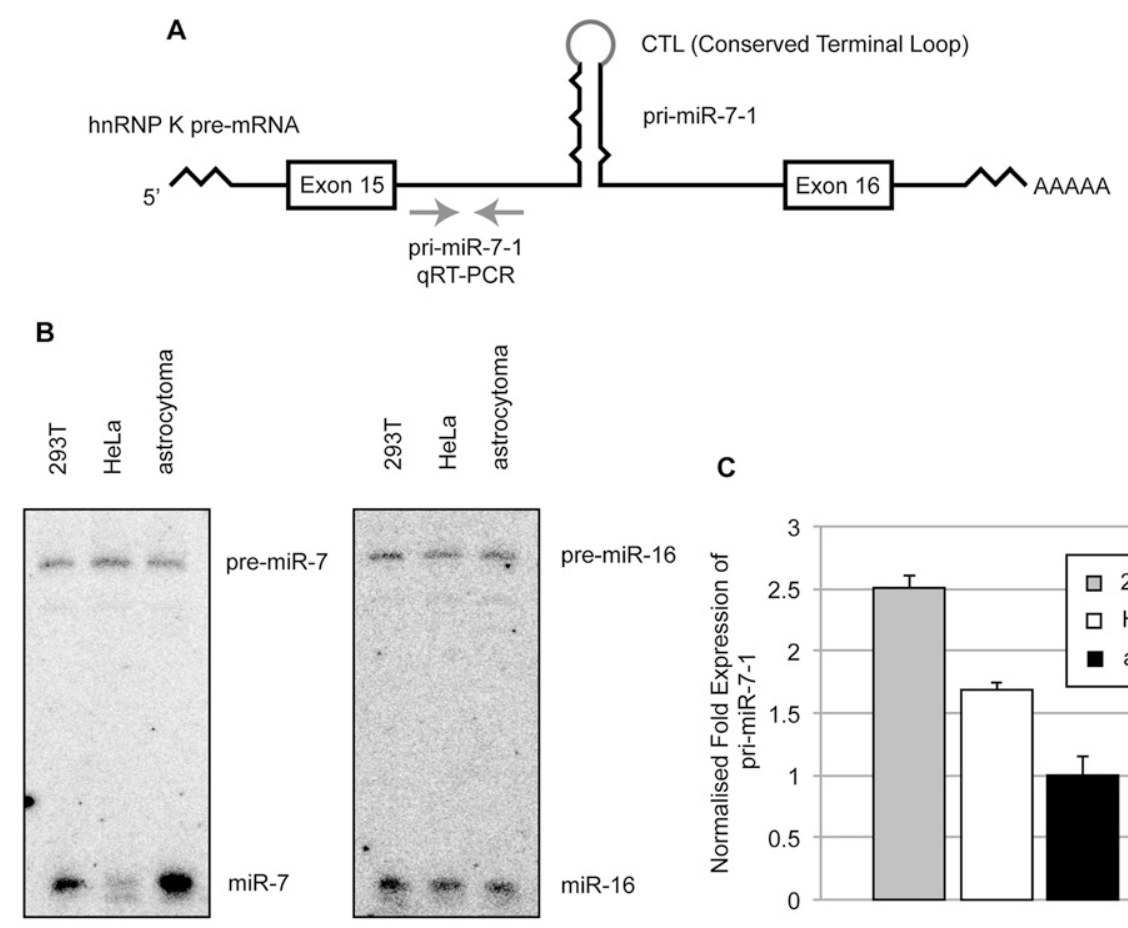

C
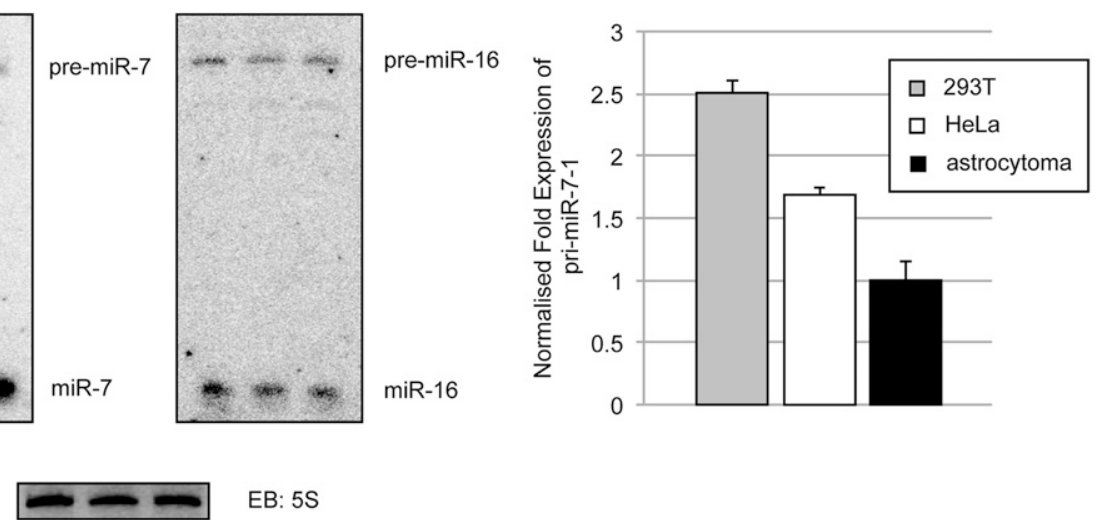

Figure 1. The biogenesis of miR-7 is regulated post-transcriptionally. $(A)$ Schematic of the segment of the hnRNP K pre-mRNA that harbors the pri-miR-7-1 stem-loop region in intron 15. The CTL of pri-miR-7-1 is indicated in gray. Arrows represent relative positions of qRT-PCR primers used to measure pri-miR-7-1 levels. (B) Northern blot analysis of total RNA from astrocytoma 1321N1, 293T, and HeLa cells shows high, medium, and low levels of miR-7, respectively. In contrast, miR-16 shows similar abundance in the three cell lines. As a loading control, ethidium bromide staining of 5S rRNA is shown. (C) Real-time qRT-PCR on total RNA from 293T (gray bar), HeLa (white bar), and astrocytoma $1321 \mathrm{~N} 1$ (black bar) cells shows high, medium, and low levels of pri-mR-7-1, respectively. The values were normalized to GAPDH mRNA levels. The fold change was plotted relative to values derived from astrocytoma cells, which were set to 1 . Mean values and standard deviations (SD) of three independent qRT-PCRs are shown. 
human tissues (Yanai et al. 2005). Despite this observation, miR-7 appears to be present predominantly in neural and pancreatic tissues (Landgraf et al. 2007; Hsu et al. 2008). There are two other miR-7 loci in the human genome, pri-miR-7-2 and pri-miR-7-3; however, their expression relative to pri-miR-7-1 is $\sim 100$-fold lower (Yanai et al. 2005). Here, we sought to unravel the mechanism of tissuespecific regulation of miR-7 biogenesis. We recapitulated the tissue-specific expression of miR-7 in a subset of human cell lines. In the astrocytoma cell line $1321 \mathrm{~N} 1$, which represents human neural tissue, miR-7 was highly abundant (Fig. 1B). The expression of miR-7 in the nonneural HeLa cell line was much lower, whereas an intermediate level of expression was observed in human embryonic kidney (293T) cells (Fig. 1B). In stark contrast to the levels of mature miR-7, the relative levels of pri-miR-7-1 were lowest in the astrocytoma cell line (Fig. 1B,C). The discrepancy between the relative expression of the miR-7 primary transcript and its corresponding mature miRNA points to the role of post-transcriptional regulation in controlling its abundance in a tissue-specific manner. We observed similar levels of pre-miR-7, which could indicate that differential Dicer processing could be the regulatory mechanism (Fig. 1B). Alternatively, miR-7 abundance could be controlled in the nucleus by differential activity of Microprocessor, with similar levels of pre-miR-7-1 simply reflecting that this step is not rate-limiting.

miR-7 is inhibited by cell type-specific factors associated with the pri-miR-7-1 TL

Tissue-specific post-transcriptional regulation of miRNA abundance can be achieved by two nonexclusive mechanisms. First, there may be a positive factor present in a tissue or a given cell type, in which the tissue-enriched miRNA is abundant. Second, there may be a negative factor present in all of the tissues or cell types that harbor low levels of this miRNA. First, we investigated a role for Microprocessor in miR-7-1-regulated processing. We performed pri-miRNA in vitro processing assays in extracts from HeLa and astrocytoma cells. We observed that the Microprocessor-mediated processing that results in the production of pre-miR-7-1 was not efficient in HeLa cell extracts (Fig. 2A), whereas the accumulation of pre-miR7-1 products from pri-miR-7-1 processing in astrocytoma cell extracts was substantial (Fig. 2A). Importantly, Drosha and DGCR8 levels were even higher in HeLa than in astrocytoma cell extracts (Supplemental Fig. S1A). Additionally, pri-miRNA processing in HeLa cell extracts depleted of Drosha or DGCR8 validated the identity of the pre-miRNA products (Supplemental Fig. S2). pri-miR7-1 processing with equal amounts of premixed HeLa and astrocytoma cell extracts resulted in a much lower accumulation of pre-miR-7-1 compared with the reaction in astrocytoma cell extracts alone (Fig. 2A). Importantly, the same concentration of astrocytoma cell extracts without the addition of HeLa extracts was able to support efficient pri-miR-7-1 processing (Fig. 2A). Processing of a control pri-let-7a-1 was more efficient in HeLa than in astrocytoma cell extracts (Supplemental Fig. S1B). While we cannot rule out a contribution of regulated Dicer processing, the results presented here clearly establish that HeLa cell extracts contain an inhibitor of Microprocessormediated miR-7 processing.

The post-transcriptional regulation of miRNA biogenesis can be exerted by trans-acting factors that bind to the CTL of pri-miRNAs (Michlewski et al. 2008; Krol et al. 2010). Interestingly, pri-miR-7-1 has a TL that is well conserved throughout vertebrate species (Michlewski et al. 2008). Therefore, we opted to investigate whether the CTL of pri-miR-7-1 contributes to its biogenesis. Importantly, we found that addition of an unlabeled wild-type pri-miR-7-1 TL RNA sequence caused derepression of pri-miR-7-1 processing in HeLa cell extracts (Fig. 2B). The same competitor had only mild effects on the in vitro processing of pri-let-7a-1 (Supplemental Fig. S3). Importantly, a control competitor in the form of a mutated pri-miR-7-1 harboring the TL sequence of miR30a (pri-let-7a-1/30a) did not cause derepression of primiR-7-1 processing in HeLa cells (Fig. 2B). Accordingly, the in vitro processing of pri-miR-7-1 harboring the CTL from pri-miR-30a was more efficient in HeLa extracts than wild-type pri-miR-7-1 or a pri-miR-7-1/16 TL mutant (Fig. 2C,D), which could be due to its sequence composition. In summary, these results demonstrate that Microprocessor-mediated miR-7 processing is inhibited by factors associated with the pri-miR-7-1 TL present in HeLa cells. These experiments strongly suggest that the tissue-specific control of miR-7-1 biogenesis is operating at the level of the nuclear step of miR-7-1 biogenesis.

SILAC combined with RNase-assisted RNA pull-down on the pri-miR-7-1 CTL identifies putative miR-7 biogenesis factors

To establish the identity of the miR-7 biogenesis factors that may repress pre-miR-7 production in a cell typespecific manner, we used a novel method combining RNase-assisted RNA pull-down of a truncated wild-type pri-miR-7-1 CTL (Michlewski and Caceres 2010b) followed by SILAC mass spectrometry. Briefly, the RNA bait was covalently attached to agarose beads, and bound proteins from HeLa and astrocytoma 1321N1 extracts were eluted by RNase to enhance the specificity of the isolation. Next, we used SILAC for quantitative comparison by mass spectrometry of proteins bound to different RNA baits or to the beads (Fig. 3A). We compared the binding of proteins from HeLa cell extracts labeled with heavy Arg/Lys isotopes to the pri-miR-7-1 TL with the binding of proteins from HeLa cell extracts labeled with light Arg/Lys isotopes to the beads. After sorting, we identified 14 proteins with a greater than fivefold enrichment of binding to the pri-miR-7-1 CTL (Fig. 3B). Significantly, all of the identified proteins were RNA-binding proteins, some of which were already implicated in the regulation of miRNA biogenesis (Krol et al. 2010). Next, we used our method on the pri-miR-7-1 CTL using equal amounts of HeLa and astrocytoma cell extracts labeled with heavy and light Arg/Lys isotopes, respectively. The majority of the proteins associated with the pri-miR-7-1 
A

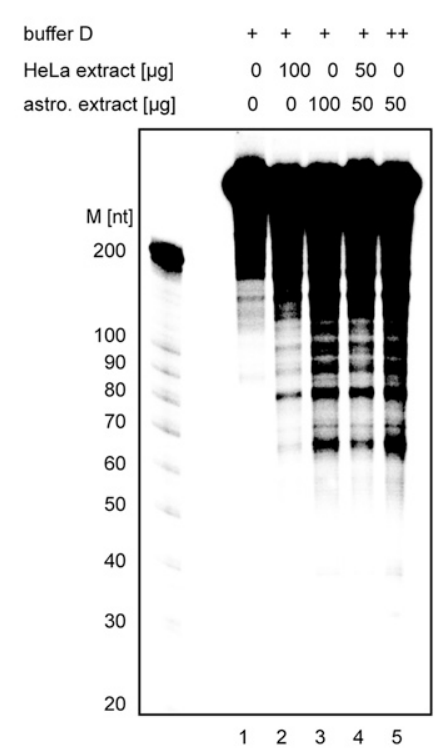

C

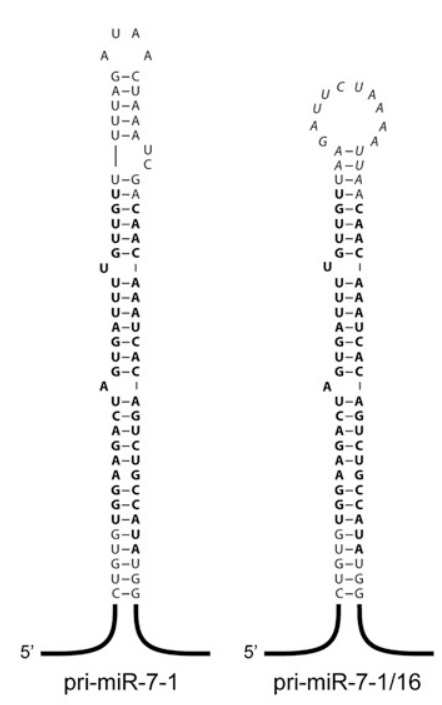

B

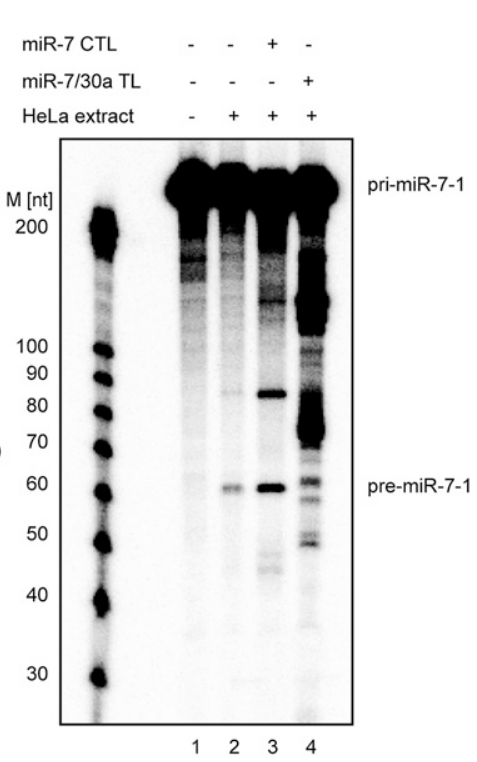

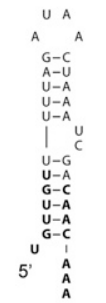

miR-7-1 CTL

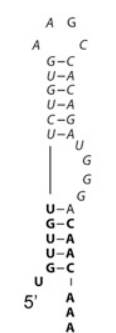

$\operatorname{miR}-7-1 / 30 \mathrm{a} T \mathrm{~L}$

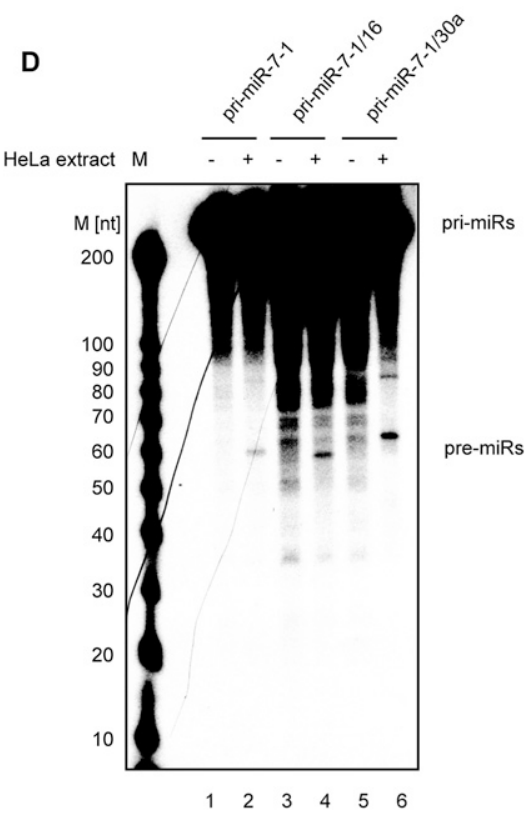

Figure 2. Processing of pri-miR-7-1 is inhibited by nonneural CTL-binding factors. $(A)$ In vitro processing of pri-miR-7-1 in HeLa and astrocytoma $1321 \mathrm{~N} 1$ cell extracts. Radiolabeled primary miR-7-1 transcripts $\left(50 \times 10^{3} \mathrm{cpm}\right.$ [counts per minute], $\left.\sim 20 \mathrm{pmol}, 665 \mathrm{nM}\right)$ were incubated in the presence of $50 \%(\mathrm{w} / \mathrm{v})$ total HeLa extract (lane 2), 50\% (w/v) astrocytoma 1321N1 extract (lane 3), 25\% (w/v) HeLa extract plus $25 \%(\mathrm{w} / \mathrm{v})$ astrocytoma $1321 \mathrm{~N} 1$ extract (lane 4), or $25 \%(\mathrm{w} / \mathrm{v})$ astrocytoma $1321 \mathrm{~N} 1$ extract (lane 5). Lane 1 shows the negative control with no extract added. Products were analyzed on an $8 \%$ polyacrylamide gel. (M) RNA size marker. (B) In vitro processing of pri-miR-7-1 is derepressed in the presence of unlabeled truncated wild-type pri-miR-7-1. pri-miR-7-1 was incubated with HeLa extracts (lane 2) with 1 nmol of miR-7-1 CTL (lane 3) or 1 nmol of pri-miR-7-1/30a CTL (lane 4). Lane 1 shows the negative control with no extract added. Analysis was performed as described in $A$. Schematic of the RNA secondary structure of the wild-type miR-7-1 CTL and mutant miR-7-1/30a TL is shown on the right. $(C)$ Predicted secondary structures of wild-type pri-miR-7-1 and CTL mutants. The wild-type terminal loop sequence was replaced with the pri-miR-16 or pri-miR-30a TLs, resulting in pri-miR-7-1/16 and pri-miR-7-1/30a hybrids, respectively. $(D)$ The processing of pri-miR-7-1 is inhibited by sequences present in its terminal loop. Radiolabeled pri-miR-7-1 (lane 2), pri-miR-7-1/16 (lane 4), and pri-miR-7-1/ 30a (lane 6) transcripts $\left(50 \times 10^{3} \mathrm{cpm}, 20 \mathrm{pmol}, 665 \mathrm{nM}\right)$ were incubated in the presence of $50 \%(\mathrm{w} / \mathrm{v})$ total HeLa extract. Lanes 1,3 , and 5 show negative controls with no extract added. Products were analyzed on an $8 \%$ polyacrylamide gel. (M) RNA size marker.

TL demonstrated similar binding efficiencies in HeLa and astrocytoma cell extracts (Supplemental Table S1). Notably, the MSI2 protein exhibited a twofold increase in binding to the pri-miR-7-1 CTL in HeLa cell extracts compared with astrocytoma cell extracts (Fig. 3B). To demonstrate the specificity and sensitivity of our method, we performed validation using Western blot analysis of select identified proteins and other abundant RNA-binding 
A

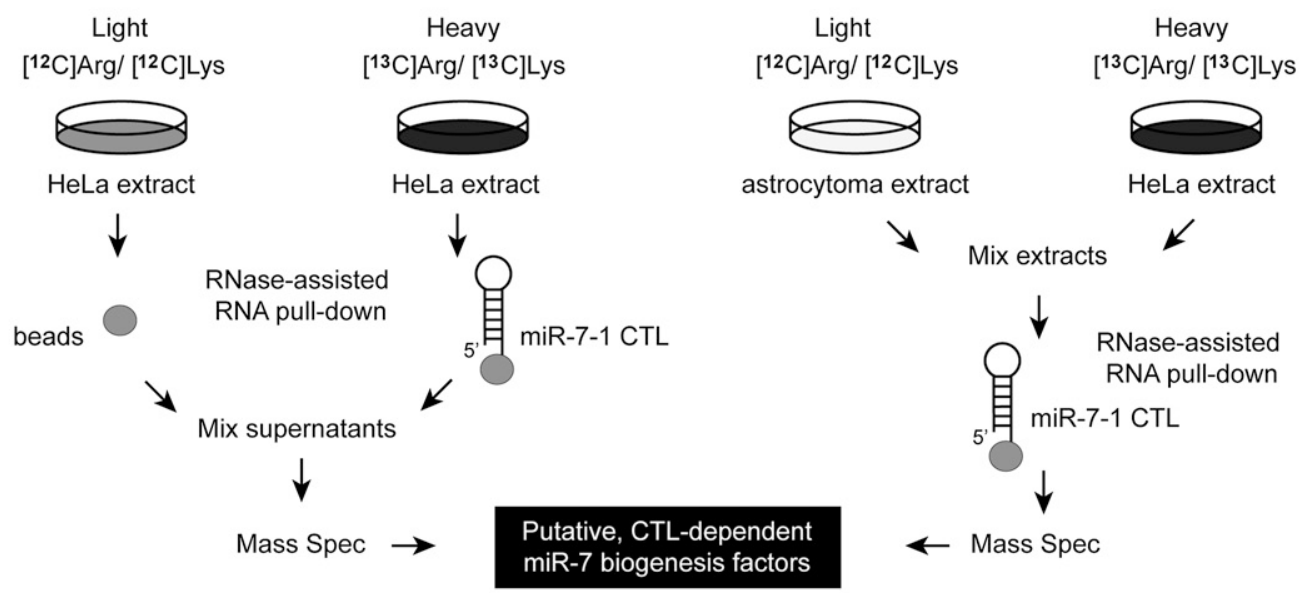

B

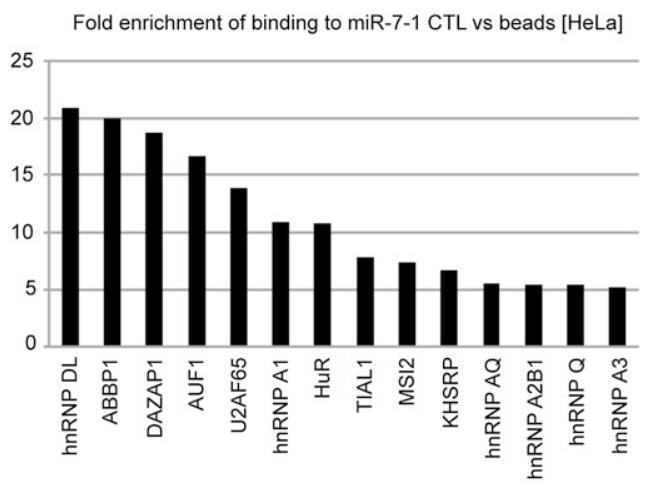

Fold change of binding to miR-7-1 CTL [HeLa] vs miR-7-1 CTL [astrocytoma]

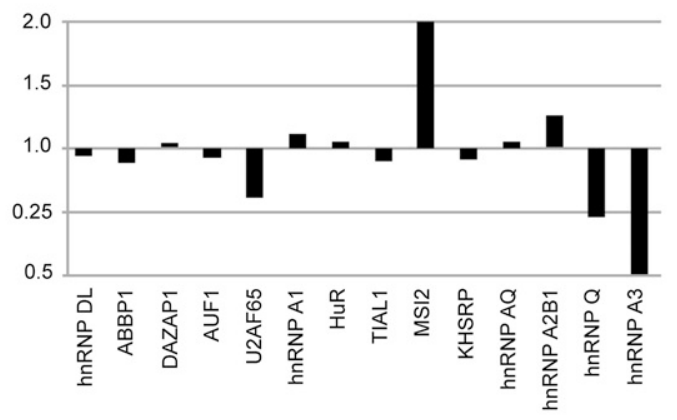

C
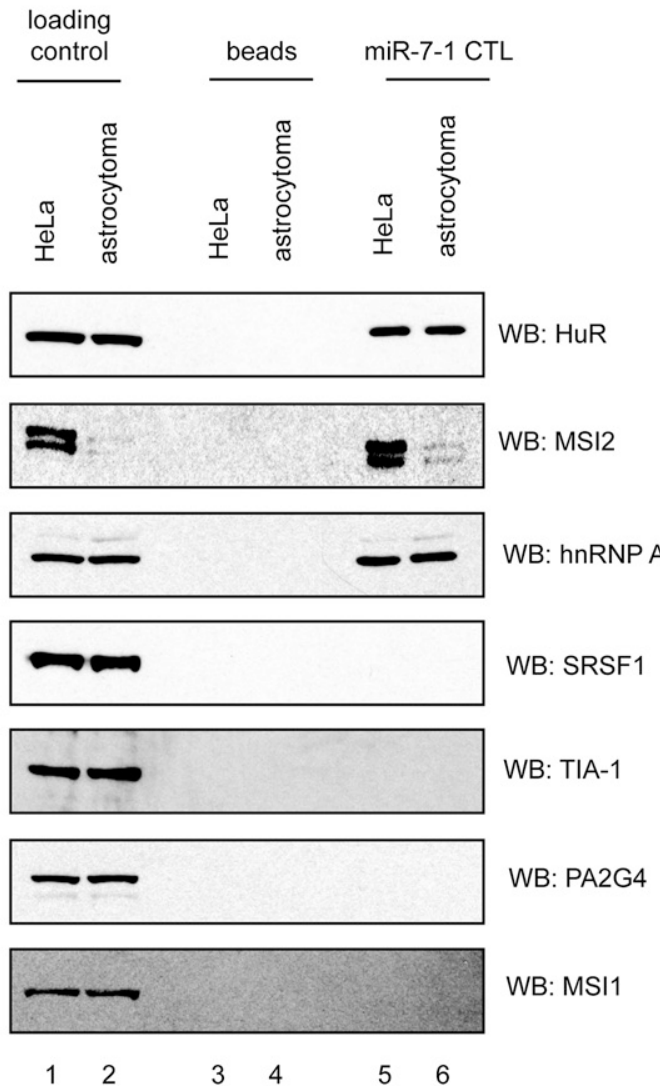

Figure 3. SILAC combined with RNase-assisted RNA pull-down reveals putative miR-7 biogenesis factors. $(A)$ Schematic of the method. The left panel shows the strategy used to distinguish background noise that arises from proteins binding to the agarose beads compared with proteins that specifically bind to the miR-7-1 CTL RNA. HeLa cells were grown in "light" medium containing ${ }^{12} \mathrm{C}_{6}$ arginine and ${ }^{12} \mathrm{C}_{6}$-lysine or in "heavy" medium containing ${ }^{13} \mathrm{C}_{6}$-arginine and ${ }^{13} \mathrm{C}_{6}$-lysine. Next, RNase-assisted RNA pull-down was performed on either agarose beads incubated with extracts from "light" HeLa cells or beads with a covalently linked miR-7-1 CTL incubated with extracts from "heavy" HeLa cells. After RNase treatment, the resulting supernatants were mixed and subjected to quantitative mass spectrometry. The right panel represents a way of identifying protein factors in the extracts from different cells or experimental conditions that differentially bind to the bait RNA. The workflow is similar to the one described above, with different extracts, premixed and incubated with the same complexes of agarose beads with a covalently linked miR-7-1 CTL. Finally, quantitative mass spectrometry identified RNA-binding proteins that, in the case of miR-7-1 CTL, are putative miR-7 biogenesis factors. $(B)$ The top graph represents the fold enrichment of proteins that bind to the miR-7-1 CTL compared with the beads alone in experiments with "light" and "heavy" HeLa cell extracts. The fold enrichment cutoff was set to 5. The bottom graph represents the fold enrichment of proteins that bind to the miR-7-1 CTL in experiments with "heavy" HeLa cell extracts compared with "light" astrocytoma cell extracts. $(C)$ Western blot analysis of miR-7-1 CTL RNA pull-down with HeLa and astrocytoma cell extracts on select proteins identified in $B$ (HuR, MSI2, and hnRNP A1) and control proteins (SRSF1, TIA-1, PA2G4, and MSI1). Lanes 1 and 2 represent 100 $\mu \mathrm{g}$ of loading control of HeLa and astrocytoma cell extracts, respectively. Lanes 3 and 4 show reactions with beads alone. Lanes 5 and 6 represent miR-7-1 CTL RNA pull-down with HeLa and astrocytoma cells extracts, respectively. 
proteins that were not identified in the assay. The HuR (ELAVL1) and hnRNP A1 proteins were pulled down with similar efficiency by the pri-miR-7-1 CTL in both HeLa and astrocytoma cell extracts (Fig. 3C). Importantly, MSI2 was specifically enriched in HeLa cells compared with astrocytoma cells. Moreover, MSI2 was also substantially enriched in the pri-miR-7-1 CTL RNA pull-down with HeLa cell extracts (Fig. 3B). Importantly, other abundant RNA-binding proteins, such as serine/arginine-rich splicing factor 1 (SRSF1), T-cell-restricted intracellular antigen-1 (TIA-1), proliferation-associated 2G4 (PA2G4), or MSI1, were not pulled down by the pri-miR-7-1 CTL, which verifies the high specificity and selectivity of this method.

To further investigate the proteins that are responsible for the post-transcriptional regulation of miR-7 biogenesis, we performed RNA pull-down with the pri-miR-7-1 CTL and the pri-miR-7-1/30a TL mutant (Supplemental Fig. S4A), which exhibited different activity in the in vitro processing assays (Fig. 2). Western blot analysis methods showed that the binding of MSI2 to the pri-miR-7-1 CTL was highly specific (Supplemental Fig. S4B). We observed a substantial enrichment of MSI2 binding to the wild-type pri-miR-7-1 CTL compared with the pri-miR-7-1/30a TL mutant. Interestingly, several other proteins, including TIA1 cytotoxic granule-associated RNA-binding proteinlike 1 (TIAL1), deleted in azoospermia-associated protein 1 (DAZAP1), and HuR, were also enriched in the pri-miR7-1 TL pull-down, albeit to a lesser extent (data not shown). Importantly, the binding efficiencies of hnRNP Al to the pri-miR-7-1 CTL and to the pri-miR-7-1/30a TL were similar (Supplemental Fig. S4B). Furthermore, the SRSF1 protein was pulled down by the pri-miR-7-1/30a TL much more efficiently than by the pri-miR-7-1 CTL. Altogether, we identified a comprehensive set of proteins that specifically bind to the pri-miR-7-1 CTL, which we consider putative inhibitors of miR-7 biogenesis.

\section{HuR and MSI2 inhibit miR-7 biogenesis in vivo through converging pathways}

To determine whether these pri-miR-7-1 CTL-binding factors function as inhibitors of miR-7 processing, we analyzed the relative levels of mature miR-7 and pri-miR7-1 by quantitative RT-PCR (qRT-PCR) upon selective depletion of HuR and/or MSI2. We monitored the efficiency of siRNA-mediated depletion in HeLa cells by Western blot analysis (Fig. 4A). The highly abundant PA2G4 and SRSF1, which did not exhibit binding preferences for the pri-miR-7-1 CTL, served as controls. Notably, individual knockdowns of HuR and MSI2 resulted in an approximately twofold increase in the relative abundance of endogenous miR-7 in HeLa cells, in which miR-7 is normally of low abundance (Fig. 4B). In contrast, PA2G4, SRSF1, and TIAL1 knockdowns did not change the levels of miR-7 (Fig. 4B; data not shown). Crucially, the double knockdown of HuR and MSI2 also resulted in an approximately twofold increase in miR-7 abundance (Fig. 4B). The lack of cumulative effect of the double knockdown compared with the individual knockdowns suggests that HuR and MSI2 may regulate miR-7 levels in vivo through converging pathways. Importantly, the levels of let-7a miRNA remained unchanged throughout (Fig. 4B). More importantly, the levels of both miR-7 and let-7a primary transcripts were largely unchanged upon knockdown of HuR, MSI2, or control proteins (Fig. 4C). This result strongly suggests that the HuR and MSI2 proteins regulate miR-7 abundance in vivo at the posttranscriptional level. Global small RNA sequencing (RNA-seq) profiling of miRNAs upon MSI2 and HuR knockdown revealed significant increases of the miR-7 levels: $172 \%\left(P\right.$-value $\left.=1.95 \times 10^{-31}\right)$ and $224 \%(P$-value $=$ $1.82 \times 10^{-66}$ ) for MSI2 and HuR, respectively (Fig. 4D). Clustal Omega alignment of selected pri-miRNA sequences (pri-miR-505, pri-miR-92a-1, pri-miR-224, and pri-miR-7-1), which code for miRNAs up-regulated by both HuR and MSI2 knockdown, revealed a common U-rich motif in their TLs (Supplemental Fig. S5). Although further analysis would be required, we hypothesize that this motif could be important for MSI2/HuR-mediated regulation of miRNA biogenesis. Crucially, comparison of data sets from HuR and MSI2 RNAi showed very little difference, pointing to a cooperative mode of miRNA biogenesis regulation by these two proteins.

\section{HuR recruits MSI2 to the pri-miR-7-1 CTL in vitro and in vivo}

To gain further insight into the mechanism of miR-7 inhibition, we investigated whether MSI2 and HuR interact with each other. We coexpressed T7 epitope-tagged MSI2 (pCG T7-MSI2) with untagged HuR (pCDNA3$\mathrm{HuR}$ ) in HeLa cells and studied their association by immunoprecipitation-Western blot, which revealed an efficient coimmunoprecipitation (Fig. 5A). RNase treatment, validated by RT-PCR of immunoprecipitated primiR-7-1, slightly decreased the efficiency of coimmunoprecipitation of $\mathrm{HuR}$, which indicates that the interaction between MSI2 and HuR is most likely mediated through both RNA-dependent and RNA-independent mechanisms. Importantly, the reciprocal coimmunoprecipitation of MSI2 by HuR confirmed this interaction (Fig. 5B). Notably, consistent with our previous experiments, we did not detect an interaction between MSI2 or HuR and SRSF1 (Fig. 5A,B). We further determined whether MSI2 could still bind the pri-miR-7-1 CTL in the absence of HuR. RNA pull-down of the pri-miR-7-1 CTL in HeLa extracts depleted of HuR revealed that MSI2 binding to the pri-miR-7-1 CTL was greatly reduced (Fig. 5C). Finally, RNA immunoprecipitation assays confirmed the MSI2 dependence on HuR to bind to the pri-miR-7-1 transcript in vivo (Fig. 5D). Intriguingly, RNAi of MSI2 and HuR resulted in a decreased association of pri-miR-7-1 with DGCR8, most likely indicating a decreased pool of pri-miR-7 transcripts available to bind DGCR8 resulting from an increased rate of Microprocessor activity in the absence of either protein (Fig. 5D). Crucially, neither HuR nor MSI2 could pull down pri-let-7a-1 in the RNA immunoprecipitation assay (Fig. 5E). Importantly, the level of DGCR8 RNA immunoprecipitation with pri-let-7a-1 remained unchanged in experiments carried out on both 
Choudhury et al.
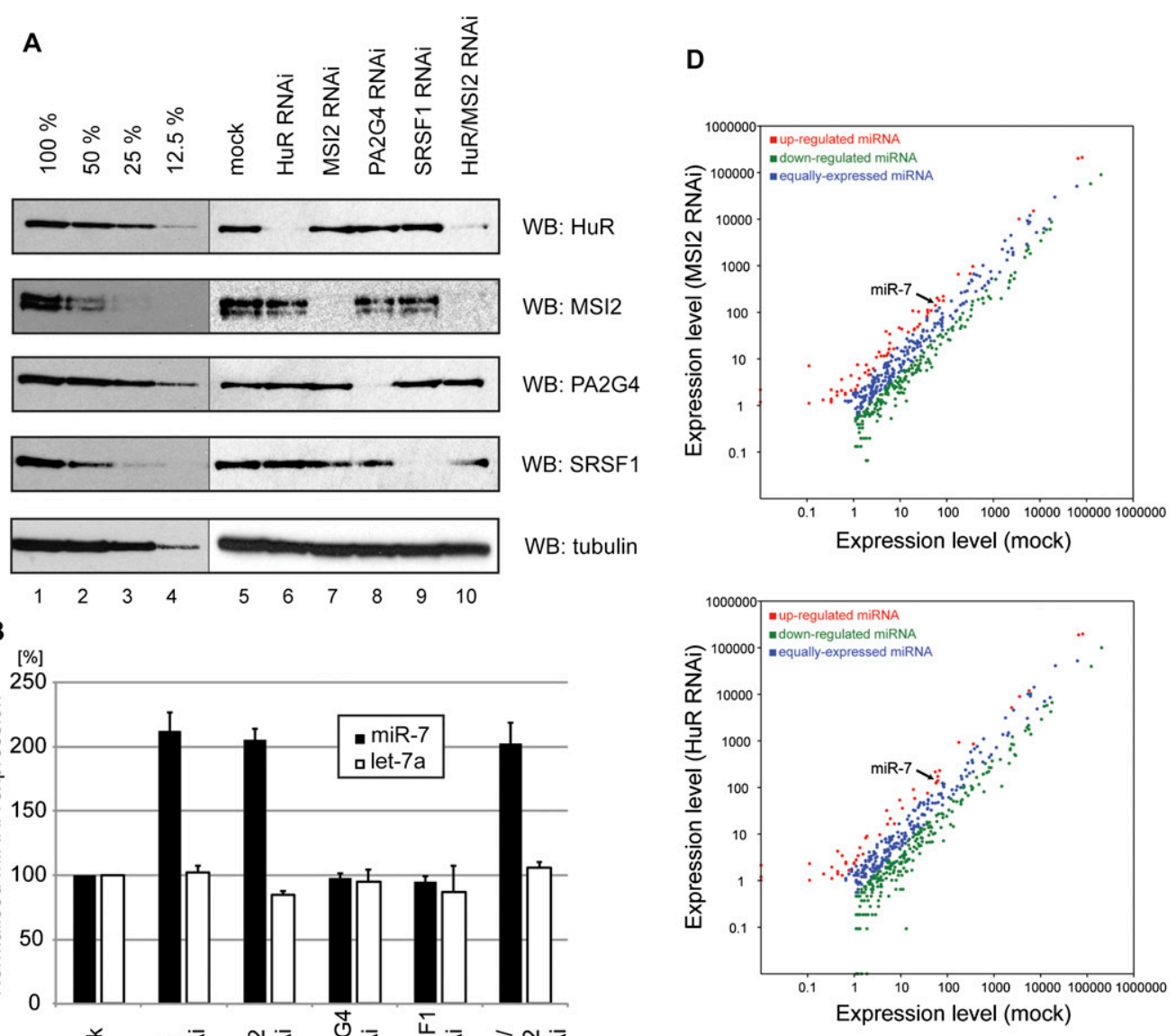

B
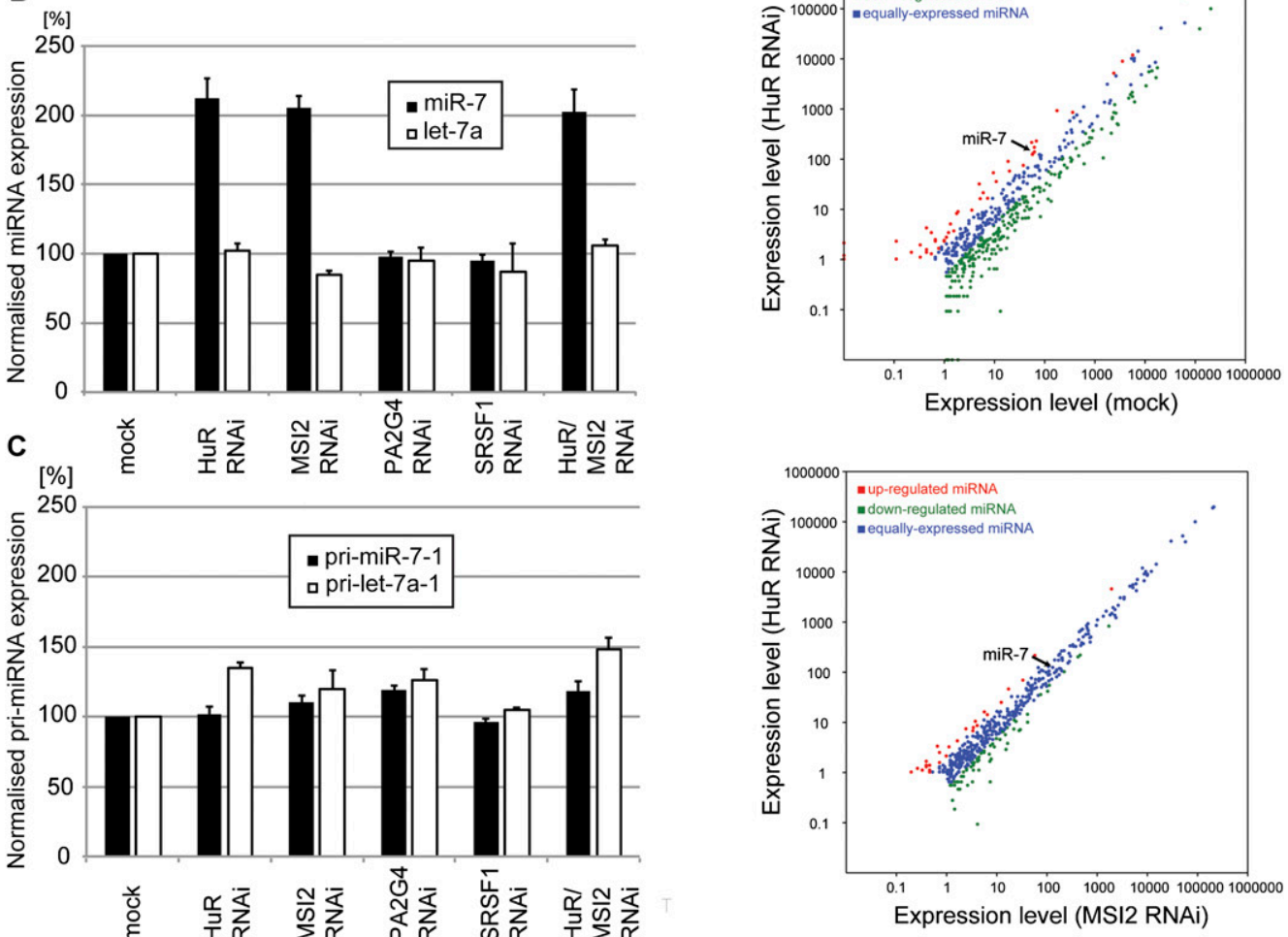

Figure 4. MSI2 and HuR regulate miR-7 biogenesis in vivo through converging pathways. $(A)$ Western blot analysis of protein extracts from HeLa cells depleted of HuR (lane 6), MSI2 (lane 7), PA2G4 (lane 8), SRSF1 (lane 9), or both HuR and MSI2 (lane 10) using RNAi. Lanes 1-4 show serial dilutions of total protein extracts, providing estimation of the Western blot assay linearity and the limit of detection. Lane 5 shows a mock-transfected control. Lanes 6-10 show Western blot results. (B) Real-time qRT-PCR of miRNAs from HeLa cells depleted of HuR, MSI2, PA2G4, SRSF1, and HuR/MSI2 reveals a substantial increase in the levels of miR-7 (black bars) upon HuR depletion, MSI2 depletion, or combined HuR/MSI2 depletion. These values were normalized to miR-16 levels. The fold change in the corresponding miRNA abundance mediated by RNAi was plotted relative to values from a mock-transfected control, which were set to 100. Mean values and SDs of three independent experiments are shown. No significant changes in the levels of let-7a were observed in any case. $(C)$ Real-time qRT-PCR on pri-miRNAs from cells depleted as in $B$ shows a lack of substantial change in the relative levels of the corresponding pri-miR-7-1 (black bars) and pri-let-7a-1 (white bars) transcripts. The values were normalized to GAPDH levels. The fold change in the corresponding pri-miRNA abundance mediated by RNAi was plotted relative to values from a mock-transfected control, which were set to 100. (D) Small RNA-seq analysis of MSI2 and HuR knockdown. The top graph shows a comparison of mock-treated HeLa cells and MSI2-depleted cells (MS2 RNAi), and the middle graph shows a comparison of mocktreated HeLa cell and HuR-depleted cells, whereas the bottom panel shows a comparison between MSI2-depleted cells and HuRdepleted cells. mir-7 is indicated with an arrow. Library construction, sequencing, and data analysis were performed by BGI (Beijing Genomics Institute). 
A

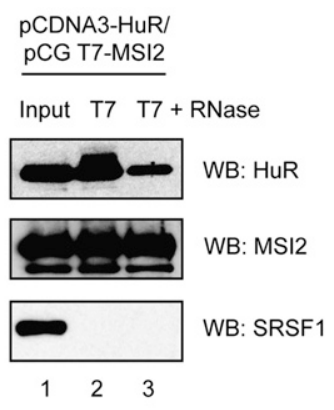

B
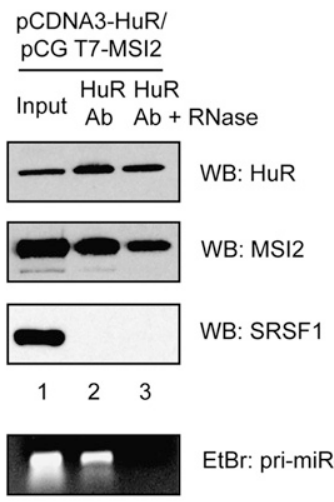

EtBr: pri-miR-7-1

$\begin{array}{lll}1 & 2 & 3\end{array}$

D

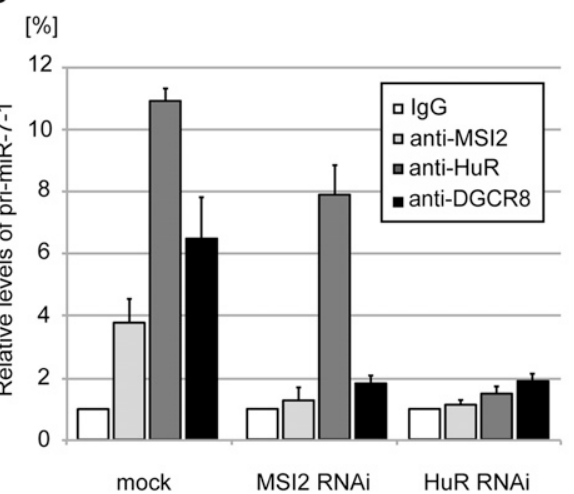

C

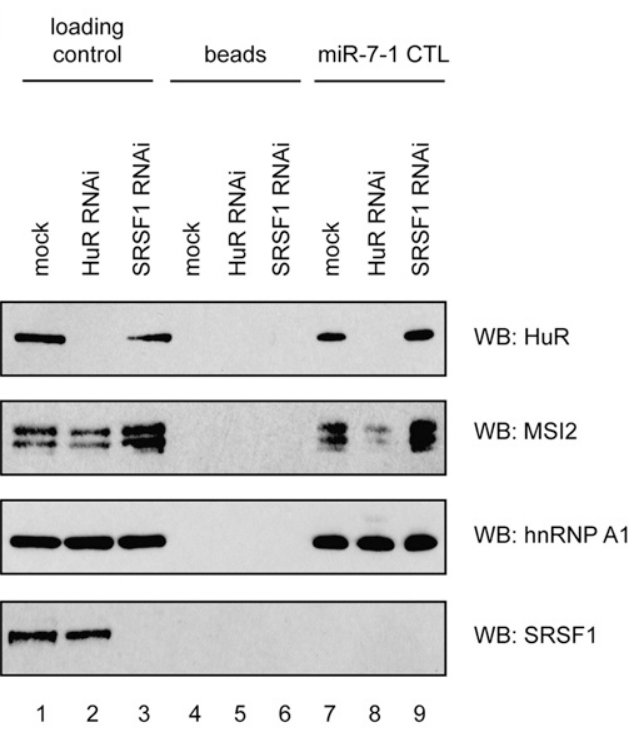

E

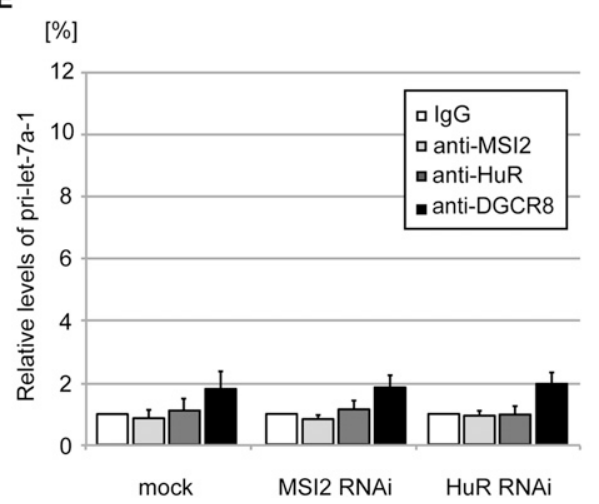

Figure 5. HuR recruits MSI2 to the pri-miR-7-1 CTL through a direct interaction. (A) Extracts prepared from HeLa cells transfected with pCG T7-MSI2 and pCDNA3-HuR were incubated with T7 agarose. (Lane 2) The bound proteins were separated on a 10\% SDSpolyacrylamide gel and analyzed by Western blotting with anti-HuR, anti-MSI2, or anti-SRSF1 antibodies. (Lane 3) Alternatively, the immunoprecipitate was treated with RNases A/T1 prior to loading on the gel. Lane 1 was loaded with $2 \%$ of the amount of extract used for each immunoprecipitation. (B) Extracts prepared from HeLa cells transfected with pCG T7-MSI2 and pCDNA3-HuR were incubated with protein A beads and anti-HuR antibody. (Lane 2) The bound proteins were separated on a $10 \%$ SDS-polyacrylamide gel and analyzed by Western blotting with anti-HuR, anti-MSI2, or anti-SRSF1 antibodies. (Lane 3) Alternatively, the immunoprecipitate was treated with RNases A/T1 prior to loading on the gel. Lane 1 was loaded with $2 \%$ of the amount of extract used for each immunoprecipitation. Ethidium bromide-stained $1 \%$ agarose gel of RT-PCR assay detecting pri-miR-7-1 in input; anti-HuR immunoprecipitation and anti-HuR immunoprecipitation with RNase treatment are shown in lanes 1-3, respectively. (C) Western blot analysis of miR-7-1 CTL RNA pull-down in mock-, HuR- or SRSF1-depleted HeLa cell extracts for HuR, MSI2, hnRNP A1, and SRSF1. Lanes 1-3 show loading control of HeLa cell extracts from mock, HuR RNAi, and SRSF1 RNAi, respectively. Lanes 4-6 show reactions with beads only. Lanes 7-9 represent miR-7-1 CTL RNA pull-down in HeLa cell extracts from mock, HuR RNAi, and SRSF1 RNAi, respectively. $(D, E)$ RNA immunoprecipitation assays of formaldehyde cross-linked HeLa cells using anti-MSI2, anti-HuR, and anti-DGCR8 antibodies, coupled with protein-A agarose beads. qRT-PCR analysis was performed on TRIzol LS-isolated RNA with primers detecting pri-miR-7-1 $(D)$ and pri-let-7a-1 $(E)$ transcripts. The percentage of immunoprecipitation was plotted relative to values derived from IgG controls, which were set to 1. Mean values and SDs of three independent experiments are shown.

MSI2- and HuR-depleted cells (Fig. 5E). These results provide an explanation for concomitant effects of MSI2 and $\mathrm{HuR}$ on the regulation of miR-7 biogenesis. Furthermore, the mechanistic role of HuR may be to assist MSI2 binding to the pri-miR-7-1 CTL, which is the actual effector that inhibits miR-7 biogenesis. 
Recombinant HuR and MSI2 bind to pri-miR-7-1 and stabilize its structure

To map the precise binding sites of HuR and/or MSI2 in pri-miR-7-1 and to determine whether this binding influences the RNA architecture and/or thermodynamic properties that might negatively regulate its processing, we analyzed pri-miR-7-1 secondary structure in the presence or absence of recombinant HuR and/or MSI2 proteins by footprint analysis. The predicted structure of the pri-miR-7-1 RNA was validated by in vitro probing of radiolabeled pri-miR-7-1 RNA with lead ions-Pb (II), which cleaves single-stranded and relaxed RNA residues; ribonuclease $\mathrm{T} 1$, which cleaves exposed phosphodiester bonds after guanosines; and ribonuclease V1, which cleaves regions of dsRNA (Fig. 6). Addition of recombinant MSI2 (Fig. 6C) to the reactions did not leave noticeable $\mathrm{Pb}$ (II) footprints along the pri-miR-7-1 structure while inducing weak ribonuclease $\mathrm{T} 1$ and ribonuclease V1 footprints along the pri-miR-7-1 structure. Conversely, recombinant HuR (Fig. 6C) masked otherwise pronounced $\mathrm{Pb}$ (II) and $\mathrm{T} 1$ cuts in the pri-miR-7-1 CTL region as well as other regions of the stem-loop structure (Fig. 6). HuR binding also resulted in the appearance of a few additional cuts, which could have originated from unspecific cleavage or RNA structural rearrangements. Importantly, addition of HuR and MSI2 together resulted in a prominent increase in ribonuclease V1 cleavage of the pri-miR-7-1 stem-loop region (Fig. 6). This implies a global increase of the pri-miR-7-1 rigidity, which is also confirmed by much weaker $\mathrm{Pb}$ (II) cuts in the corresponding region. In light of Drosha cleavage activity, which requires auxiliary helicase activity (Fukuda et al. 2007), stabilization of the pri-miRNA structure could exert an inhibitory effect.

A role for HuR and MSI2 in the negative regulation of pri-miR-1 processing was confirmed using in vitro processing assays in astrocytoma cell extracts. Addition of MSI2, but not of HuR, inhibited the processing of primiR-7-1, confirming a direct role for MSI2 in blocking Drosha processing (Supplemental Fig. S6). This could imply that endogenous levels of HuR are sufficient and not limiting for the MSI2-mediated inhibition of pri-miR7-1 Drosha cleavage or, alternatively, that MSI2 does not require HuR for its recruitment in vitro. Finally, using electrophoretic gel mobility shift analysis (EMSA) of a $5^{\prime}$ 32P-labeled pri-miR-7-1 transcript, we observed that unlike MSI2, HuR was able to efficiently bind to pri-miR-7-1 (Fig. 6D). Moreover, addition of MSI2 protein to the primiR-7-1/HuR complex resulted in a noticeable supershift, indicating that MSI2 is recruited to pri-miR-7-1 through HuR. The pri-miR-7-1/HuR/MSI2 complex was efficiently competed by increasing excess of unlabeled miR-7-1 CTLs but not unspecific RNA without apparent HuR-binding sites.

$H u R$ and MSI2 regulate miR-7 biogenesis in a human neuronal differentiation system of SH-SY5Y cells

To confirm the physiological relevance of our findings, we used a human neuronal differentiation model of neuroblastoma SH-SY5Y cells. When treated with alltrans retinoic acid (RA) and subsequently with brainderived neurotrophic factor (BDNF), SH-SY5Y cells give rise to nearly pure populations of human neuron-like cells (Encinas et al. 2000). Such differentiated cells stop dividing and express numerous neuronal markers, such as microtubule-associated protein 2A (MAP2A). Following this differentiation protocol, we observed progressive morphological changes, manifesting in neurite outgrowth and reduced size of the cell body (Supplemental Fig. 7A). Western blot analysis of neuronal marker MAP2A confirmed successful neuronal differentiation of SH-SY5Y cells (Supplemental Fig. 7B). Importantly, expression of both MSI2 and HuR was significantly reduced only at the last stage of differentiation, after treatment with BDNF (Supplemental Fig. 7B). To see whether HuR and MSI2 are inhibiting miR-7 biogenesis during SH-SY5Y differentiation, we tested the levels of mature and primary miRNA transcripts by qRT-PCR. Treatment of SH-SY5Y cells with RA did not result in significant changes in miR-7 levels (Supplemental Fig. 7C); however, treatment with BDNF resulted in an approximately twofold increase in the relative abundance of miR-7 (Supplemental Fig. 7C), displaying a negative relationship of miR-7 levels with HuR and MSI2 expression patterns. The levels of let-7 were also elevated, most likely due to differentiationdependent repression of $\operatorname{Lin} 28$ protein. In contrast, the levels of miR-302a did not change significantly during differentiation (Supplemental Fig. 7C). Notably, the levels of miR-7 and miR-302a primary transcripts were largely unchanged throughout SH-SY5Y differentiation (Supplemental Fig. 7D). To ensure that HuR and MSI2 regulate miR-7 biogenesis in SH-SY5Y cells, we used siRNAmediated depletion, as in HeLa cells in Figure 4. Individual knockdowns of HuR and MSI2 as well as double knockdown of HuR and MSI2 resulted in an approximately twofold increase in the relative abundance of miR-7 (Supplemental Fig. S8). PA2G4 and SRSF1 knockdowns did not change the levels of miR-7 (Supplemental Fig. S8). The levels of both the miR-7 and let-7a primary transcripts remained unchanged. Altogether, these results ascertain the physiological relevance of MSI2/ HuR-dependent inhibition of miR-7 biogenesis.

MSI2 KO mice display elevated levels of miR-7 in selected tissues without apparent change in the pri-miR-7-1 abundance

Finally, we took advantage of a MSI2 KO model to illustrate the physiological significance of our findings. Western blot analysis of MSI2 in selected tissues from a wild-type mouse revealed that MSI2 exists as multiple isoforms in all tissues analyzed except for the brain and is almost undetectable in the liver (Fig. 7A,B). In contrast, $\mathrm{HuR}$ is detected at very low levels in the brain, the liver, and muscle-derived samples. Analysis of miR-7 levels by qRT-PCR confirmed its enrichment in the brain of a wild-type mouse (Fig. 7C). In contrast, the levels of pri-miR-7-1 did not change significantly across tissues with the exception of the thymus, where relatively low 
A

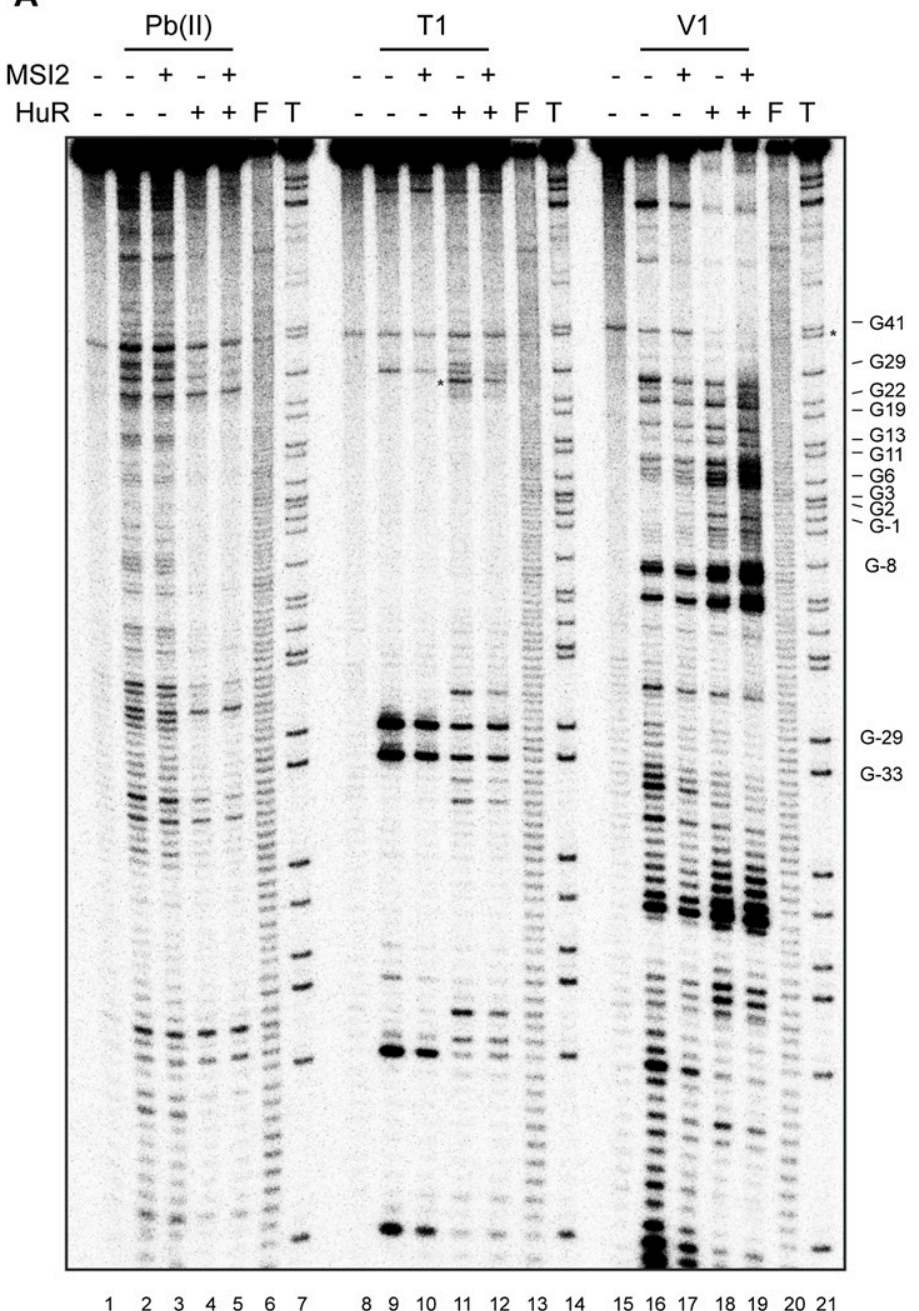

B

pri-miR-7-1

pri-miR-7-1

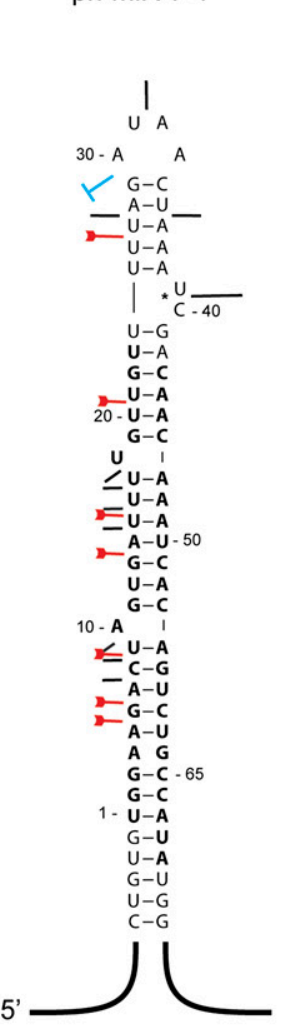

$+\mathrm{HuR} / \mathrm{MSI} 2$

\section{$\mathrm{Pb}(\mathrm{II})-\mathrm{II}_{\mathrm{I}} \quad \mathrm{T} 1-\mathrm{TT}_{\mathrm{T}} \quad \mathrm{V} 1-\mathrm{IT}_{\mathrm{T}}$<smiles>[AlH2]</smiles>

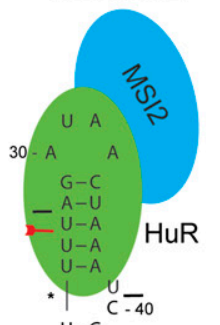

$\mathrm{U}-\mathrm{G}$

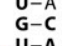

20- U-A

$-\mathbf{U}-\mathbf{A}$
$\mathbf{G}-\mathbf{C}$

$u_{U-A}^{U-A}$

U-A
$\mathbf{U}-\mathbf{A}$

$\mathbf{U}-\mathbf{A}$
$\mathbf{A}-\mathbf{U}-50$

A-U- 50 U-A G-C $10-\mathbf{A}^{-}$

U-A
C-G
A-U

A-U

G-C

A G

G-C

1- U-A

U-U

G-U

U-G

$5^{\prime}$
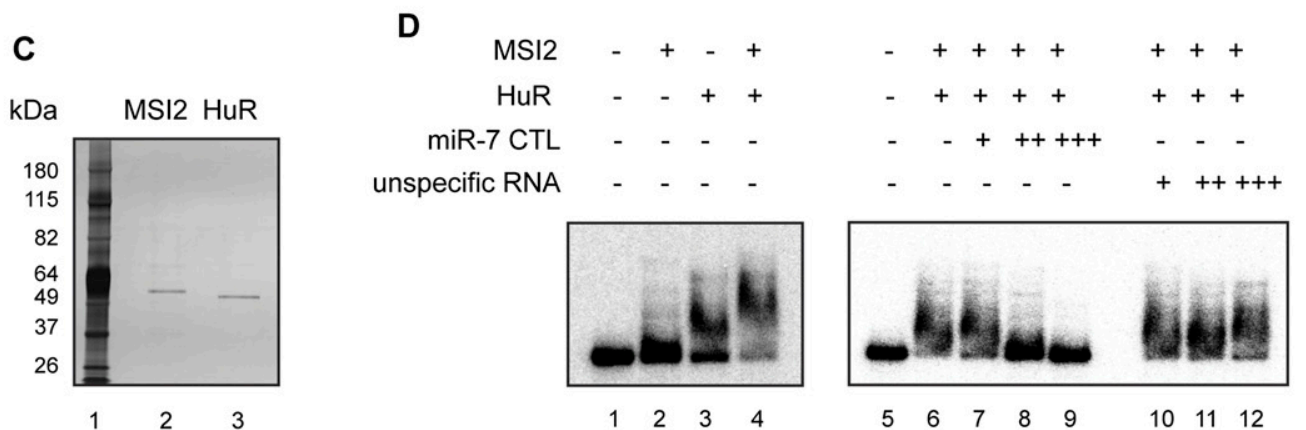

pri-miR-7-1/

protein complex free pri-miR-7-1

Figure 6. Recombinant HuR binds directly to the pri-miR-7-1 CTL and recruits MSI2, increasing the rigidity of the stem-loop structure. (A) Structure probing and footprint analysis of the pri-miR-7-1 in complex with HuR and/or MSI2 proteins. Cleavage patterns were obtained for 5' 32P-labeled pri-miR-7-1 transcript $\left(100 \times 10^{3} \mathrm{cpm}, \sim 40 \mathrm{pmol}, 4 \mu \mathrm{M}\right)$ incubated in the absence $($ lanes 1,2,8,9,15,16) or presence of recombinant MSI2 (200 ng, $500 \mathrm{nM})$ (lanes 3,10,17), HuR (200 ng, $500 \mathrm{nM})($ lanes 4,11,18), and both proteins (200 ng, 500 $\mathrm{nM})$ (lanes 5,12,19) treated with $\mathrm{Pb}$ (II) lead ions $(0.5 \mathrm{mM})$, ribonuclease $\mathrm{T} 1(1.5 \mathrm{U} / \mu \mathrm{L})$, and ribonuclease $\mathrm{V} 1(0.025 \mathrm{U} / \mathrm{mL}) . \mathrm{F}(1 \mathrm{anes}$ $6,13,20)$ and $\mathrm{T}$ (lanes 7,14,21) denote nucleotide residues subjected to partial digestion with formamide (every nucleotide) or ribonuclease T1 (G-specific cleavage), respectively. Electrophoresis was performed in a $6 \%$ polyacrylamide gel under denaturing conditions. The positions of selected G residues are indicated. Nucleotides are numbered from the $5^{\prime}$ site of Drosha cleavage. $(B)$ Proposed structure of free and HuR/MSI2-bound pri-miR-7-1 (additionally supported by the RNA pull-down results presented in Fig. 3; Supplemental Fig. 3). The sites and intensities of cleavages generated by structure probes (presented below) within the pre-miR-7-1 region are shown. The asterisk indicates selected intrinsic or protein-induced in-line autocatalytic RNA cleavages. $(C)$ Silver-stained $4 \%-12 \%$ Novex Tri-Bis SDS-PAGE of recombinant MSI2 (100 ng) (lane 2) and recombinant HuR (100 ng) (lane 3) shows the quality of the proteins (OriGene Technologies). (Lane 1) BenchMark prestained protein ladder indicates approximate molecular weights. The proteins migrate similarly to corresponding endogenous proteins detected by relevant antibodies. $(D)$ EMSA of pri-miR-7-1 with the MSI2 and HuR proteins. Electrophoresis was performed in a 5\% polyacrylamide gel under native conditions. Prior to electrophoresis, $5^{\prime}$ $32 \mathrm{P}$-labeled pri-miR-7-1 transcript $\left(50 \times 10^{3} \mathrm{cpm}, \sim 20 \mathrm{pmol}, 2 \mu \mathrm{M}\right)$ was incubated without proteins (lane 1) or in the presence of recombinant MSI2 (200 ng, $500 \mathrm{nM}$ ) (lane 2), HuR (200 ng, $500 \mathrm{nM}$ ) (lane 3), or both proteins (200 ng, $500 \mathrm{nM}$ ) (lane 4). miR-7-1 and unspecific indicate unlabeled RNA competitors; (+) 5 pmol; (++) 50 pmol; (+++) 500 pmol. 

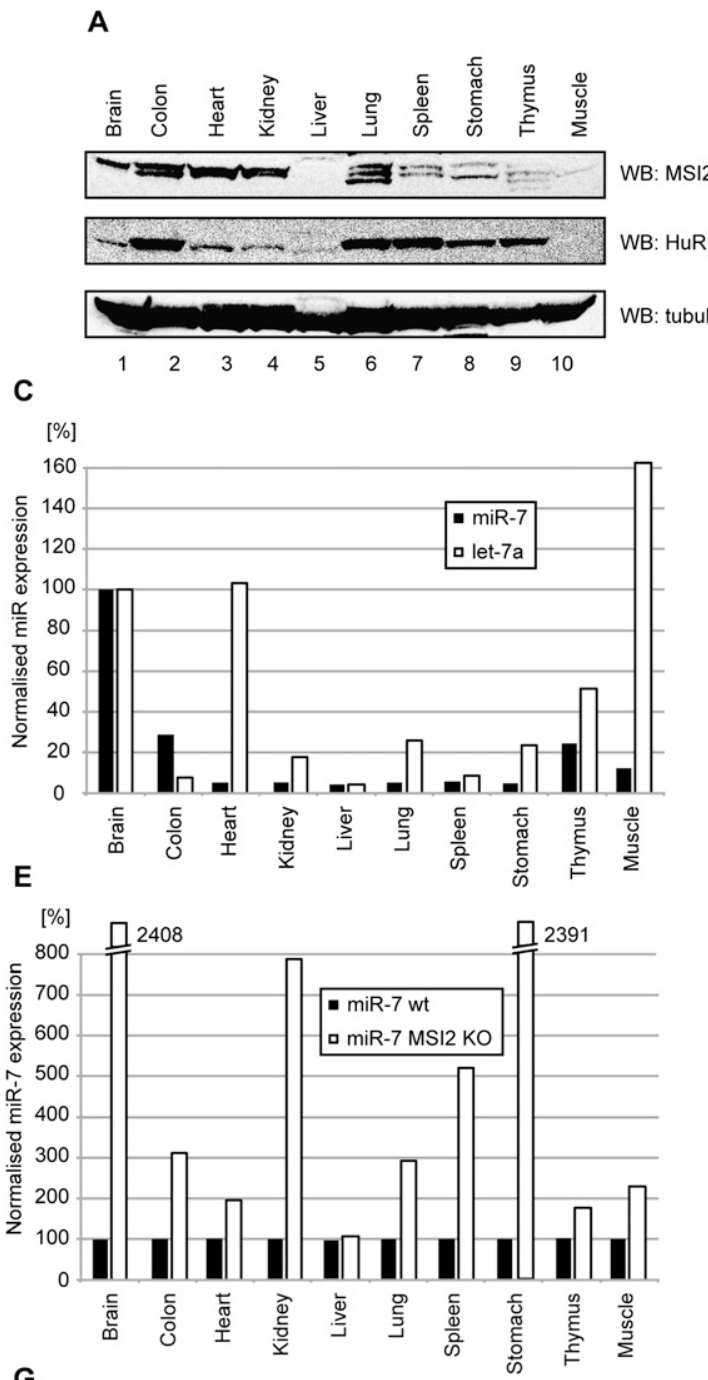

F

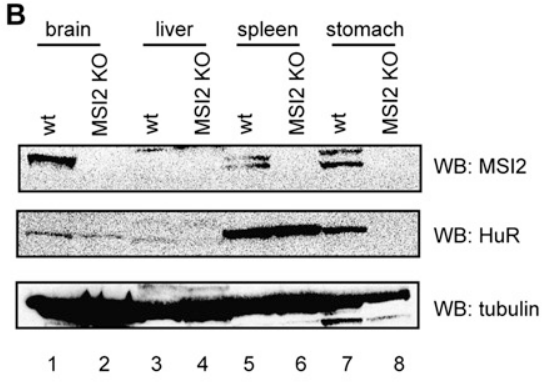

\section{D}
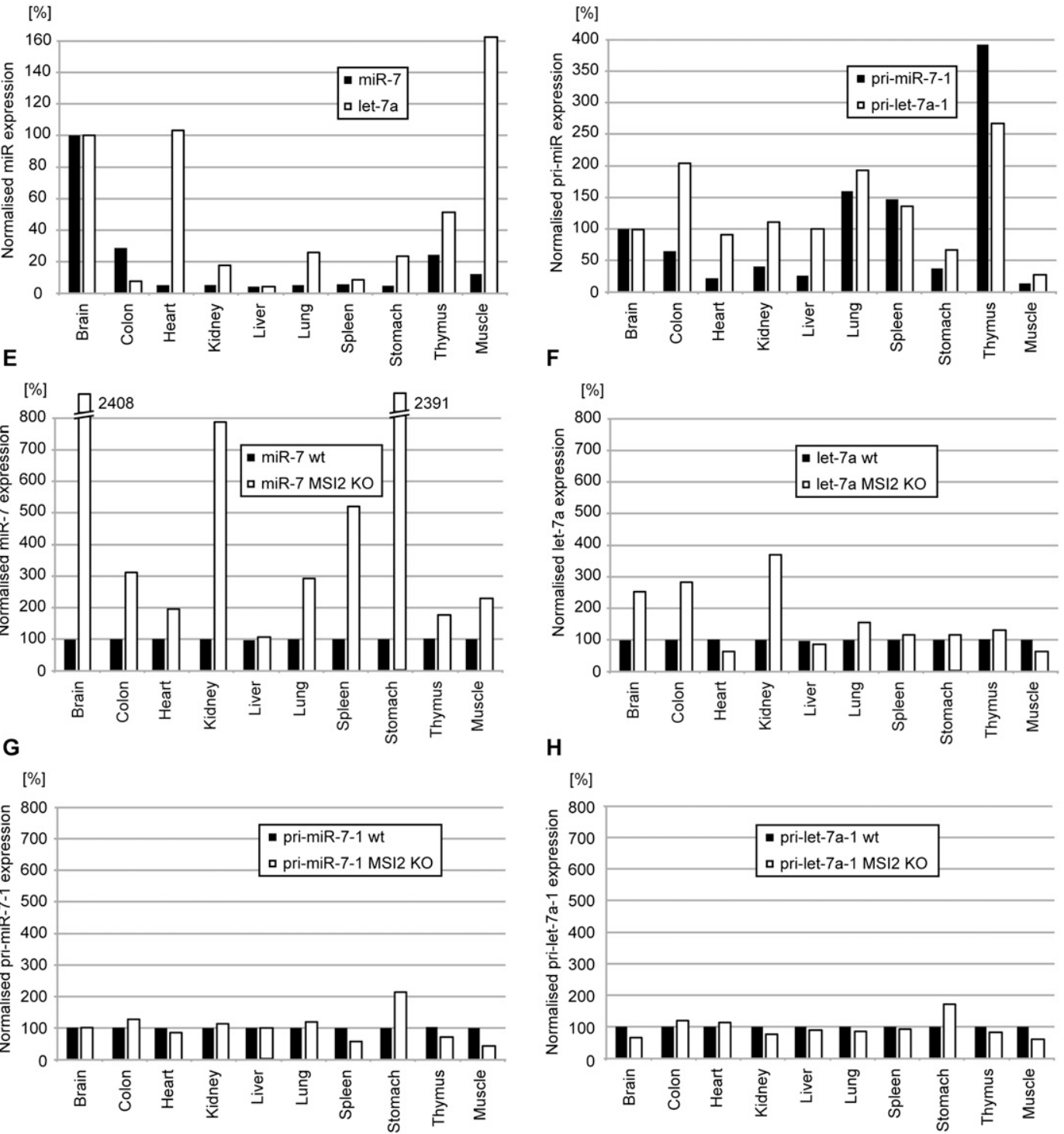

Figure 7. Brain-enriched miR-7 is up-regulated in a MSI2 KO mouse. $(A)$ Western blot analysis of protein extracts from wild-type mouse tissues using anti-MSI2, anti-HuR, and anti-tubulin. (Lane 1) Brain. (Lane 2) Colon. (Lane 3) Heart. (Lane 4) Kidney. (Lane 5) Liver. (Lane 6) Lung. (Lane 7) Spleen. (Lane 8) Stomach. (Lane 9) Thymus. (Lane 10) Muscle. (B) Western blot analysis of protein extracts from selected MSI2 KO mouse tissues. Lanes 1, 3, 5, and 7 indicate extracts from a wild-type mouse, whereas lanes 2, 4, 6, and 8 show proteins derived from a MSI2 KO mouse. $(C)$ Real-time qRT-PCR on miRNAs from $1 \mu \mathrm{g}$ of total RNA from select wild-type mouse tissues reveals a substantial enrichment of miR-7 (black bars) in brain tissue and a different pattern of let-7a (white bars) in select tissues. The values were normalized to $5 \mathrm{~S}$ levels. The fold change of miR abundance was plotted relative to the values from brain total RNA, which were set to 100. $(D)$ Real-time qRT-PCR on pri-miRNAs from samples as shown in $A$ show a lack of significant correlation with the abundance of the corresponding mature miRNAs (correlation coefficient $=0.16, P$-value $=0.33$ ). Values were normalized to GAPDH levels. The fold change of pri-miRNA abundance was plotted relative to the values from brain total RNA, which were set to 100. (E) Real-time qRT-PCR on miR-7 from total RNA samples derived from wild-type (black bars) and MSI2 KO (white bars) mice show a large increase in the levels of miR-7 in MSI2 KO tissues. Values were normalized to 5S levels. The fold change of miR-7 abundance was plotted relative to values derived from the wild-type mouse, which were set to 100. $(F)$ Real-time qRT-PCR on let-7a from total RNA samples derived from wild-type (black bars) and MSI2 KO (white bars) mice. Data are presented as in $E .(G, H)$ Real-time qRT-PCR on pri-miR-7-1 and pri-let-7a-1 from samples as shown in $E$ show very little difference between the wild-type and MSI2 KO mice. Values were normalized to GAPDH levels. The fold change of pri-miR abundance was plotted relative to the values from the wild-type mouse, which were set to 100 . 
levels of mature miR-7 are found (Fig. 7D). This strongly supports the existence of post-transcriptional control of miR-7 abundance in mammalian cells. Similar results were obtained when human RNA from selected tissues was analyzed (Supplemental Fig. S9). Crucially, miR-7 levels were elevated in the MSI2 KO mouse from twofold to 20-fold depending on the tissue type, with the highest increases observed in the brain and stomach (Fig. 7E). Let7a displayed a modest increase in only a few tissues when compared with miR-7 (Fig. 7F). Importantly, the relative abundance of pri-miR-7-1 and pri-let-7a-1 transcripts remained similar in the MSI2 KO and the wild-type mice, with exception of stomach tissue, where we observed a twofold increase in pri-miR-7-1 and pri-let-7a-1 abundance (Fig. 7G,H).

In summary, we revealed a novel molecular mechanism that controls brain-enriched miRNA biogenesis by neural-depleted factors. Our results strongly suggest a role for the MSI2 and HuR proteins in binding to pri-miR-7-1 and the negative regulation of tissue-specific miR-7 production at the post-transcriptional level in mammalian tissues.

\section{Discussion}

In eukaryotic cells, miRNA levels are tightly controlled, and their dysregulation is a hallmark of many human diseases, including cancer (Davis and Hata 2010). Increasing evidence suggests that the biogenesis of miRNAs is regulated at different steps by a variety of protein factors that bind to the CTL elements of pre-miRNAs and primiRNAs (Winter et al. 2009; Krol et al. 2010). For example, the Lin28 proteins (Lin28a and Lin28b) mediate the CTL-dependent inhibition of let-7 biogenesis in undifferentiated cells and at early stages of embryonic development (Rybak et al. 2008; Viswanathan et al. 2008). It has been shown that the binding of Lin28a to the CTL of pre-let-7 induces 3 '-terminal uridylation through the recruitment of TUT4 polymerase (Heo et al. 2008, 2009; Jones et al. 2009; Nam et al. 2011), thereby preventing efficient processing of pre-let-7 by Dicer, which in turn leads to active degradation of the transcript (Heo et al. 2009). Additionally, it has been demonstrated that Lin $28 \mathrm{~b}$ functions in the nucleus by sequestering primary let-7 transcripts and inhibiting their processing by Microprocessor (Piskounova et al. 2011). We showed recently that the RNA-binding protein hnRNP Al acts as a negative regulator of let-7a processing in somatic cells that lack Lin28 (Michlewski and Caceres 2010a). hnRNP A1 binds to the CTL of pri-let-7a-1 and inhibits its processing by Drosha by interfering with the binding of the KSRP protein, which is known to promote let-7a biogenesis (Trabucchi et al. 2009).

Here, we reveal the first example of defined factors that control tissue-enriched miRNA maturation. We demonstrate a lack of positive correlation between the levels of mature miR-7 and the pri-miR-7-1 transcript in human cells and tissues, which is indicative of the existence of a post-transcriptional mechanism controlling miR-7 abundance. Previously, it was suggested that the SR protein
SRSF1 positively regulates the processing of miR-7 by binding to the pri-miR-7-1 stem and competing with canonical miRNA processing factors (Wu et al. 2010). In our experimental conditions, the efficient knockdown of SRSF1 in HeLa cells did not result in a noticeable change in miR-7 levels (Fig. 4). Recently, it was shown that HuR depletion in HeLa cells results in a significant induction of miR-7 without an apparent change in the levels of the pri-miR-7-1 transcript (Lebedeva et al. 2011). While confirming this observation, we also found other miRNAs whose abundance is changed upon HuR depletion. Importantly, cross-linking immunoprecipitation (CLIP) analysis of HuR-binding sites failed to detect the CTL region of pri-miR-7-1 or its immediate flanking sequence. Here, we demonstrate that HuR inhibits miR-7 biogenesis by binding to the CTL of pri-miR-7-1. The failure to detect CLIP tags over the CTL region of the pri-miR-7-1 may be due to the rapid turnover of miR-7 containing the $h n R N P$ $K$ intron. Notably, the HuR protein is expressed ubiquitously throughout human tissues, unlike its neuronal homologs, $\mathrm{HuB}, \mathrm{HuC}$, and $\mathrm{HuD}$ (Ma et al. 1996). Furthermore, in our experiments, we detected similar levels of HuR in astrocytoma and HeLa cells expressing high and low levels of miR-7, respectively. Additionally, the CTL of pri-miR-7-1 pulled down HuR with the same efficiency from astrocytoma and HeLa cell extracts. All of these observations suggest that HuR alone is not sufficient for the repression of miRNA processing and that, in the case of miR-7, there is another factor that limits its biogenesis in most human cells and allows its expression in neural cells.

Using methodology that allows for the comprehensive characterization of proteins that bind to a defined RNA molecule in a given experimental condition, we identified the MSI2 protein, which is preferentially expressed and bound to the pri-miR-7-1 CTL in HeLa cell extracts. Recently, a similar methodology using tobramycin RNA affinity chromatography coupled with quantitative mass spectrometry was used to identify proteins that bind dengue virus untranslated regions (UTRs) (Ward et al. 2011). It was previously shown that during neurogenesis, the expression of MSI2 is lost in post-mitotic neurons (Sakakibara et al. 2001). Moreover, Northern blot analysis of the MSI2 transcript in human tissues showed low levels in the brain compared with other tissues (Barbouti et al. 2003). In agreement, we showed that the levels of both MSI2 and HuR proteins were significantly reduced during neuronal differentiation of human neuroblastoma SH-SY5Y cells and displayed an opposing expression pattern to the miR-7 abundance. It was previously noted that miR-7 levels are increased during differentiation of SH-SY5Y cells (Le et al. 2009). Crucially, we show that a MSI2 KO mouse, which displays aberrant regulation of hematopoietic stem cells (de Andres-Aguayo et al. 2011), has elevated levels of miR-7 when compared with the wild-type mouse. This up-regulation was detected without apparent changes in the levels of miR-7 primary transcript. We also validated our findings using global miRNA profiling with small RNA-seq. Independent knockdown of MSI2 and HuR resulted in a significant increase of the miR-7 levels. However, the observed change in miR-7 
levels upon HuR knockdown was lower than the one reported earlier (Lebedeva et al. 2011), being more in line with our qRT-PCR results. This discrepancy could be due to a different HeLa strain used in our study, RNAi efficiency, sample processing, and data analysis. Surprisingly, we found other miRNAs (for example, pri-miR-505, primiR-92a-1, and pri-miR-224) that are coregulated by MSI2 and HuR. It remains to be established whether these miRNAs undergo similar tissue-specific regulation of their biogenesis. In summary, all of these results strongly indicate that the MSI2 and HuR proteins have a physiological role in inhibition of miR-7 biogenesis in mammalian cells.

miR-7 is also present in pancreatic cells. Since pancreatic and neuronal differentiation lineages are closely related (Zhao et al. 2007), it will be interesting to determine whether a similar mechanism of miRNA regulation operates in pancreatic tissues. Recently, it has been demonstrated that MSI1, a close homolog of MSI2, works in conjunction with Lin28 to regulate let-7 biogenesis at the level of Drosha cleavage (Kawahara et al. 2011). Here, we demonstrate that HuR recruits MSI2 to the pri-miR7-1 CTL. Therefore, MSI2 is likely the regulatory inhibitor of miR-7 biogenesis, and the role of HuR may be limited to strengthening the interaction between the primiR-7-1 CTL and MSI2. Finally, we show that the HuR/ MSI2 complex increases the rigidity of the pri-miR-7-1 stem-loop structure. Due to the fact that the Microprocessor cleavage is dependent on DEAD-box RNA helicase activity (Fukuda et al. 2007), such stabilization provides a mechanistic clue into the inhibitory effect of MSI2/HuR on the processing of pri-miR-7.

Aberrant miRNA expression has been linked to a variety of human pathological states, including cancers (Ventura and Jacks 2009). Furthermore, analysis of gene expression in primary tumors indicates widespread defects in the post-transcriptional regulation of miRNA processing (Thomson et al. 2006; Lee et al. 2008). Crucially, miR-7 expression has been shown to be downregulated in high-grade glioblastomas without an apparent change in the levels of pri-miR-7 transcripts (Kefas et al. 2008). Dysregulation of miR-7 leads to the activation of epidermal growth factor receptor (EGFR), a protein responsible for initiating uncontrolled cell division (Nicholson et al. 2001). Interestingly, the 3' UTR of mouse EGFR does not have miR-7-binding sites while sharing binding sites with the human EGFR 3' UTR for miR-133 and miR-27 (TargetScan, release 6.2, June 2012). Thus, the physiological activity of MSI2/HuR-mediated inhibition in mice will most likely be exerted through yet unknown targets. Both HuR and MSI2 are overexpressed in numerous human malignancies, including brain cancers (Nabors et al. 2001; Hinman and Lou 2008; Moore 2010). Furthermore, MSI2 plays important roles in normal and malignant hematopoiesis (de Andres-Aguayo et al. 2012). Therefore, the identified inhibitors of miR-7 biogenesis likely have a direct role in modulating the levels of miR-7 and its targets under physiological and pathological conditions. Indeed, according to the Oncomine database (Rhodes et al. 2007), there is a clear link between the expression of EGFR, HuR, and MSI2 in glioblastoma samples (Supplemental Fig. S10). Importantly, our findings suggest that disrupting the interaction between HuR and MSI2 could have a positive effect on miR-7 and other HuR/MSI2-regulated miRNAs, implicating this interaction as a potential target for anti-cancer therapy.

\section{Materials and methods}

Cell culture, RNAi, and differentiation conditions

HeLa, human brain astrocytoma 1321N1, 293T, and neuroblastoma SH-SY5Y cells were grown in DMEM (Life Technologies) supplemented with $10 \%(\mathrm{v} / \mathrm{v})$ fetal calf serum (FCS). RNAi experiments were performed using Lipofectamine 2000 (Life Technologies) following the manufacturer's instructions. Transfected cells were incubated with the corresponding $50 \mathrm{nM}$ Silencer Select predesigned and validated siRNAs for $72 \mathrm{~h}$. Plasmids expressing recombinant proteins (500 ng per well of a six-well plate) or primiRNAs (50 ng per well of a six-well plate) were transfected for $24 \mathrm{~h}$. Differentiation of SH-SY5Y cells was performed according to a protocol described before (Le et al. 2009). In short, cells were seeded on collagen-coated plates (Life Technologies). On the following day, all-trans RA (Sigma) was added at the final concentration of $10 \mu \mathrm{M}$. After $5 \mathrm{~d}$, the cells were washed three times with DMEM and incubated with $50 \mathrm{ng} / \mathrm{mL}$ BDNF (Sigma) and incubated in serum-free medium for $4 \mathrm{~d}$.

\section{Protein expression plasmids}

The plasmid expressing HuR (pCDNA3-HuR) was a gift from Joan Steitz (Myer et al. 1997). The pri-miR-7-1 sequence was amplified by PCR with oligonucleotides miR-7-1_for_XbaI (TTTTCTAGA AAAACTGCTGCCAAAACCAC) and miR-7-1_rev_BamHI (AA AGGATCCGCTGCATTTTACAGCACCAA) and cloned into the $\mathrm{XbaI}$ and BamHI sites of the pCG-T7 mammalian expression vector (Caceres et al. 1997). MSI2 cDNA was amplified from total HeLa RNA using the SuperScript III Platinum One-Step qRT-PCR kit (Life Technologies) with oligonucleotides MSI2_for (GGCTC AGATATGGAGGCAAA) and MSI2_rev (AAAAGGAGAATGGG AAGAGAGG). Next, the MSI2 ORF was PCR-amplified using MSI2_for_XbaI (TTTTCTAGAGAGGCAAATGGGAGCCAAG GC) and MSI2_rev_BamHI (AAAGGATCCTCAATGGTATCC ATTTGTAAAG) and cloned into the XbaI and BamHI sites of the pCG-T7 mammalian expression vector to produce the pCG T7-MSI2 plasmid.

\section{Western blot analysis}

HeLa, astrocytoma, 293T, or SH-SY5Y cells were scraped and sonicated in buffer $\mathrm{D}$ as described above. Total protein extracts $(100 \mu \mathrm{g})$, proteins obtained from RNase-assisted RNA pull-down (Michlewski and Caceres 2010b), or coimmunoprecipitations were separated by SDS-PAGE and electroblotted onto nitrocellulose membranes (Whatman) in $25 \mathrm{mM}$ Tris-base, $40 \mathrm{mM}$ glycine, and $20 \%(\mathrm{v} / \mathrm{v})$ methanol in a Genie Blotter unit (Idea Scientific Companyl at $12 \mathrm{~V}$ for $1 \mathrm{~h}$. Nonspecific binding sites were blocked by incubating the membrane with 1:10 Western blocking solution (Roche) in TBST (20 mM Tris at pH 7.5, $137 \mathrm{mM} \mathrm{NaCl}, 0.1 \%$ [v/v] Tween 20). Proteins were detected using the following primary antibodies diluted in 1:20 Western blocking solution in TBST: mouse monoclonal anti-hnRNP A1 (clone 4B10; 1:1000; Santa Cruz Biotechnology), rabbit polyclonal anti-HuR (1:1000; Millipore), rabbit polyclonal anti-MSI2 (clone EP1305Y; 1:1000; Millipore), rabbit polyclonal anti-MSI1 (1:000; GeneTex), rabbit polyclonal anti-PA2G4 (1:1000; Sigma), rabbit polyclonal anti-TIA-1 (1:1000; 
Santa Cruz Biotechnology), rabbit polyclonal anti-hnRNP K (1:1000; Cell Signaling Technology), mouse monoclonal antiSRSF1 (clone 96; 1:500) (Hanamura et al. 1998), rabbit polyclonal anti-MAP2A (1:1000; Cell Signaling Technology), rabbit polyclonal anti-Drosha (1:1000; Cell Signaling Technology), rabbit polyclonal anti-DGCR8 (N-terminal, 1:1000; Sigma), and mouse-monoclonal anti- $\beta$-tubulin (1:10,000; Sigma). After washing in TBST, the blots were incubated with the appropriate secondary antibodies conjugated to horseradish peroxidase (Pierce) and detected with SuperSignal West Pico detection reagent (Thermo Scientific). The membranes were stripped using ReBlot Plus Strong Antibody Stripping solution (Chemicon), equilibrated in water, blocked in 1:10 Western blocking solution in TBST, and reprobed as described above. Proteins were also visualized by a Silver staining kit (Pierce Thermo Scientific), according to the manufacturer's instructions.

\section{MSI2 KO mouse}

The MSI2 deficient mouse cell line (MSI2 Gt/Gt) was generated by insertional mutagenesis in a large-scale gene trap screen (German Gene Trap Consortium [GGTC]) as described in de Andres-Aguayo et al. (2011). The MSI2Gt/Gt mouse is a functional knockout; thus, for the purpose of this study, we call it the MSI2 KO mouse.

\section{Acknowledgments}

We thank Sonia Guil (Bellvitge Biomedical Research Institute, Barcelona) for critical reading of the manuscript. We thank Joan Steitz (Yale University) for the kind gift of the HuR expression vector. J.F.C. was supported by the MRC and by the Wellcome Trust (grant number 095518Z/11/Z). J.R. was supported by a Wellcome Trust Senior Research Fellowship (084229). G.M. is a recipient of an MRC Career Development Award (G1000564). This work was also supported by two Wellcome Trust Centre Core Grants (077707 and 092076) and by a Wellcome Trust instrument grant (091020). N.R.C. designed, performed, and analyzed the experiments and contributed to the writing of the manuscript; F.L.A. performed and analyzed the mass spectrometry; L.A.A. and T.G. provided wild-type and MSI2 KO mouse tissue samples and discussed the mouse knockout experiments; and J.R. and J.F.C. participated in designing the experiments and in writing the manuscript. G.M. designed, performed, and analyzed the experiments, wrote the manuscript, and supervised the whole project.

\section{References}

Barbouti A, Hoglund M, Johansson B, Lassen C, Nilsson PG, Hagemeijer A, Mitelman F, Fioretos T. 2003. A novel gene, MSI2, encoding a putative RNA-binding protein is recurrently rearranged at disease progression of chronic myeloid leukemia and forms a fusion gene with HOXA9 as a result of the cryptic $\mathrm{t}(7 ; 17)(\mathrm{p} 15 ; \mathrm{q} 23)$. Cancer Res 63: 1202-1206.

Bushati N, Cohen SM. 2007. MicroRNA functions. Annu Rev Cell Dev Biol 23: 175-205.

Caceres JF, Misteli T, Screaton GR, Spector DL, Krainer AR. 1997. Role of the modular domains of SR proteins in subnuclear localization and alternative splicing specificity. I Cell Biol 138: 225-238.

Davis BN, Hata A. 2010. MicroRNA in cancer-the involvement of aberrant microRNA biogenesis regulatory pathways. Genes Cancer 1: 1100-1114.

de Andres-Aguayo L, Varas F, Kallin EM, Infante JF, Wurst W, Floss T, Graf T. 2011. Musashi 2 is a regulator of the HSC compartment identified by a retroviral insertion screen and knockout mice. Blood 118: 554-564. de Andres-Aguayo L, Varas F, Graf T. 2012. Musashi 2 in hematopoiesis. Curr Opin Hematol 19: 268-272.

Denli AM, Tops BB, Plasterk RH, Ketting RF, Hannon GJ. 2004. Processing of primary microRNAs by the Microprocessor complex. Nature 432: 231-235.

Encinas M, Iglesias M, Liu Y, Wang H, Muhaisen A, Cena V, Gallego C, Comella JX. 2000. Sequential treatment of SH-SY5Y cells with retinoic acid and brain-derived neurotrophic factor gives rise to fully differentiated, neurotrophic factor-dependent, human neuron-like cells. J Neurochem 75: 991-1003.

Eulalio A, Huntzinger E, Nishihara T, Rehwinkel J, Fauser M, Izaurralde E. 2009. Deadenylation is a widespread effect of miRNA regulation. RNA 15: 21-32.

Fabian MR, Sonenberg N, Filipowicz W. 2010. Regulation of mRNA translation and stability by microRNAs. Annu Rev Biochem 79: 351-379.

Fukuda T, Yamagata K, Fujiyama S, Matsumoto T, Koshida I, Yoshimura K, Mihara M, Naitou M, Endoh H, Nakamura T, et al. 2007. DEAD-box RNA helicase subunits of the Drosha complex are required for processing of rRNA and a subset of microRNAs. Nat Cell Biol 9: 604-611.

Gregory RI, Yan KP, Amuthan G, Chendrimada T, Doratotaj B, Cooch N, Shiekhattar R. 2004. The Microprocessor complex mediates the genesis of microRNAs. Nature 432: 235-240.

Guil S, Caceres JF. 2007. The multifunctional RNA-binding protein hnRNP A1 is required for processing of miR-18a. Nat Struct Mol Biol 14: 591-596.

Hammond SM, Bernstein E, Beach D, Hannon GJ. 2000. An RNA-directed nuclease mediates post-transcriptional gene silencing in Drosophila cells. Nature 404: 293-296.

Han J, Lee Y, Yeom KH, Kim YK, Jin H, Kim VN. 2004. The Drosha-DGCR8 complex in primary microRNA processing. Genes Dev 18: 3016-3027.

Hanamura A, Caceres JF, Mayeda A, Franza BR Jr, Krainer AR. 1998. Regulated tissue-specific expression of antagonistic pre-mRNA splicing factors. RNA 4: 430-444.

Heo I, Joo C, Cho J, Ha M, Han J, Kim VN. 2008. Lin28 mediates the terminal uridylation of let-7 precursor microRNA. Mol Cell 32: 276-284.

Heo I, Joo C, Kim YK, Ha M, Yoon MJ, Cho J, Yeom KH, Han J, Kim VN. 2009. TUT4 in concert with Lin28 suppresses microRNA biogenesis through pre-microRNA uridylation. Cell 138: 696-708.

Hinman MN, Lou H. 2008. Diverse molecular functions of $\mathrm{Hu}$ proteins. Cell Mol Life Sci 65: 3168-3181.

Hsu SD, Chu CH, Tsou AP, Chen SJ, Chen HC, Hsu PW, Wong YH, Chen YH, Chen GH, Huang HD. 2008. miRNAMap 2.0: Genomic maps of microRNAs in metazoan genomes. Nucleic Acids Res 36: D165-D169.

Hutvagner G, McLachlan J, Pasquinelli AE, Balint E, Tuschl T, Zamore PD. 2001. A cellular function for the RNA-interference enzyme Dicer in the maturation of the let-7 small temporal RNA. Science 293: 834-838.

Jones MR, Quinton LJ, Blahna MT, Neilson JR, Fu S, Ivanov AR, Wolf DA, Mizgerd JP. 2009. Zcchc11-dependent uridylation of microRNA directs cytokine expression. Nat Cell Biol 11: $1157-1163$.

Kawahara H, Okada Y, Imai T, Iwanami A, Mischel PS, Okano H. 2011. Musashil cooperates in abnormal cell lineage protein 28 (Lin28)-mediated let-7 family microRNA biogenesis in early neural differentiation. J Biol Chem 286: 1612116130.

Kefas B, Godlewski J, Comeau L, Li Y, Abounader R, Hawkinson M, Lee J, Fine H, Chiocca EA, Lawler S, et al. 2008. microRNA-7 inhibits the epidermal growth factor receptor and the Akt 
pathway and is down-regulated in glioblastoma. Cancer Res 68: 3566-3572.

Ketting RF, Fischer SE, Bernstein E, Sijen T, Hannon GJ, Plasterk RH. 2001. Dicer functions in RNA interference and in synthesis of small RNA involved in developmental timing in C. elegans. Genes Dev 15: 2654-2659.

Kim VN. 2004. MicroRNA precursors in motion: Exportin-5 mediates their nuclear export. Trends Cell Biol 14: 156-159.

Krol J, Loedige I, Filipowicz W. 2010. The widespread regulation of microRNA biogenesis, function and decay. Nat Rev Genet 11: $597-610$.

Landgraf P, Rusu M, Sheridan R, Sewer A, Iovino N, Aravin A, Pfeffer S, Rice A, Kamphorst AO, Landthaler M, et al. 2007. A mammalian microRNA expression atlas based on small RNA library sequencing. Cell 129: 1401-1414.

Landthaler M, Yalcin A, Tuschl T. 2004. The human DiGeorge syndrome critical region gene 8 and its $D$. melanogaster homolog are required for miRNA biogenesis. Curr Biol 14: 2162-2167.

Le MT, Xie H, Zhou B, Chia PH, Rizk P, Um M, Udolph G, Yang H, Lim B, Lodish HF. 2009. MicroRNA-125b promotes neuronal differentiation in human cells by repressing multiple targets. Mol Cell Biol 29: 5290-5305.

Lebedeva S, Jens M, Theil K, Schwanhausser B, Selbach M, Landthaler M, Rajewsky N. 2011. Transcriptome-wide analysis of regulatory interactions of the RNA-binding protein HuR. Mol Cell 43: 340-352.

Lee RC, Ambros V. 2001. An extensive class of small RNAs in Caenorhabditis elegans. Science 294: 862-864.

Lee Y, Ahn C, Han J, Choi H, Kim J, Yim J, Lee J, Provost P, Radmark O, Kim S, et al. 2003. The nuclear RNase III Drosha initiates microRNA processing. Nature 425: 415-419.

Lee EJ, Baek M, Gusev Y, Brackett DJ, Nuovo GJ, Schmittgen TD. 2008. Systematic evaluation of microRNA processing patterns in tissues, cell lines, and tumors. RNA 14: 35-42.

Ma WJ, Cheng S, Campbell C, Wright A, Furneaux H. 1996. Cloning and characterization of $\mathrm{HuR}$, a ubiquitously expressed Elav-like protein. J Biol Chem 271: 8144-8151.

Michlewski G, Caceres JF. 2010a. Antagonistic role of hnRNP Al and KSRP in the regulation of let-7a biogenesis. Nat Struct Mol Biol 17: 1011-1018.

Michlewski G, Caceres JF. 2010b. RNase-assisted RNA chromatography. RNA 16: 1673-1678.

Michlewski G, Guil S, Semple CA, Caceres JF. 2008. Posttranscriptional regulation of miRNAs harboring conserved terminal loops. Mol Cell 32: 383-393.

Mittler G, Butter F, Mann M. 2009. A SILAC-based DNA protein interaction screen that identifies candidate binding proteins to functional DNA elements. Genome Res 19: 284-293.

Moore MA. 2010. A cancer fate in the hands of a samurai. Nat Med 16: 963-965.

Myer VE, Fan XC, Steitz JA. 1997. Identification of HuR as a protein implicated in AUUUA-mediated mRNA decay. EMBO J 16: 2130-2139.

Nabors LB, Gillespie GY, Harkins L, King PH. 2001. HuR, a RNA stability factor, is expressed in malignant brain tumors and binds to adenine- and uridine-rich elements within the 3 ' untranslated regions of cytokine and angiogenic factor mRNAs. Cancer Res 61: 2154-2161.

Nam Y, Chen C, Gregory RI, Chou JJ, Sliz P. 2011. Molecular basis for interaction of let-7 microRNAs with Lin28. Cell 147: 1080-1091.

Nicholson RI, Gee JM, Harper ME. 2001. EGFR and cancer prognosis. Eur J Cancer 37: S9-S15.

Ong SE, Blagoev B, Kratchmarova I, Kristensen DB, Steen $\mathrm{H}_{\text {, }}$ Pandey A, Mann M. 2002. Stable isotope labeling by amino acids in cell culture, SILAC, as a simple and accurate approach to expression proteomics. Mol Cell Proteomics 1: 376-386.

Pauli A, Rinn JL, Schier AF. 2011. Non-coding RNAs as regulators of embryogenesis. Nat Rev Genet 12: 136-149.

Piskounova E, Polytarchou C, Thornton JE, LaPierre RJ, Pothoulakis C, Hagan JP, Iliopoulos D, Gregory RI. 2011. Lin28A and Lin28B inhibit let-7 microRNA biogenesis by distinct mechanisms. Cell 147: 1066-1079.

Rhodes DR, Kalyana-Sundaram S, Mahavisno V, Varambally R, Yu J, Briggs BB, Barrette TR, Anstet MJ, Kincead-Beal C, Kulkarni P, et al. 2007. Oncomine 3.0: Genes, pathways, and networks in a collection of 18,000 cancer gene expression profiles. Neoplasia 9: 166-180.

Rybak A, Fuchs H, Smirnova L, Brandt C, Pohl EE, Nitsch R, Wulczyn FG. 2008. A feedback loop comprising lin-28 and let-7 controls pre-let-7 maturation during neural stem-cell commitment. Nat Cell Biol 10: 987-993.

Sakakibara S, Nakamura Y, Satoh H, Okano H. 2001. RNAbinding protein Musashi2: Developmentally regulated expression in neural precursor cells and subpopulations of neurons in mammalian CNS. J Neurosci 21: 8091-8107.

Schulze WX, Mann M. 2004. A novel proteomic screen for peptideprotein interactions. J Biol Chem 279: 10756-10764.

Shi Y, Zhao X, Hsieh J, Wichterle H, Impey S, Banerjee S, Neveu P, Kosik KS. 2010. MicroRNA regulation of neural stem cells and neurogenesis. J Neurosci 30: 14931-14936.

Thomson JM, Newman M, Parker JS, Morin-Kensicki EM, Wright T, Hammond SM. 2006. Extensive post-transcriptional regulation of microRNAs and its implications for cancer. Genes Dev 20: 2202-2207.

Trabucchi M, Briata P, Garcia-Mayoral M, Haase AD, Filipowicz W, Ramos A, Gherzi R, Rosenfeld MG. 2009. The RNAbinding protein KSRP promotes the biogenesis of a subset of microRNAs. Nature 459: 1010-1014.

Ventura A, Jacks T. 2009. MicroRNAs and cancer: Short RNAs go a long way. Cell 136: 586-591.

Vermeulen M, Eberl HC, Matarese F, Marks H, Denissov S, Butter F, Lee KK, Olsen JV, Hyman AA, Stunnenberg HG, et al. 2010. Quantitative interaction proteomics and genomewide profiling of epigenetic histone marks and their readers. Cell 142: 967-980.

Viswanathan SR, Daley GQ, Gregory RI. 2008. Selective blockade of microRNA processing by Lin28. Science 320: 97-100.

Ward AM, Bidet K, Yinglin A, Ler SG, Hogue K, Blackstock W, Gunaratne I, Garcia-Blanco MA. 2011. Quantitative mass spectrometry of DENV-2 RNA-interacting proteins reveals that the DEAD-box RNA helicase DDX6 binds the DB1 and DB2 3' UTR structures. RNA Biol 8: 1173-1186.

Winter J, Jung S, Keller S, Gregory RI, Diederichs S. 2009. Many roads to maturity: MicroRNA biogenesis pathways and their regulation. Nat Cell Biol 11: 228-234.

Wu H, Sun S, Tu K, Gao Y, Xie B, Krainer AR, Zhu J. 2010. A splicing-independent function of SF2/ASF in microRNA processing. Mol Cell 38: 67-77.

Yanai I, Benjamin H, Shmoish M, Chalifa-Caspi V, Shklar M, Ophir R, Bar-Even A, Horn-Saban S, Safran M, Domany E, et al. 2005. Genome-wide midrange transcription profiles reveal expression level relationships in human tissue specification. Bioinformatics 21: 650-659.

Zamore PD, Tomari Y. 2005. MicroRNA biogenesis: Drosha can't cut it without a partner. Curr Biol 15: R61-R64.

Zhao W, Hirose T, Ishikawa M, Oshima Y, Hirai S, Ohno S, Taniguchi H. 2007. Neonatal pancreatic cells redifferentiate into both neural and pancreatic lineages. Biochem Biophys Res Commun 352: 84-90. 


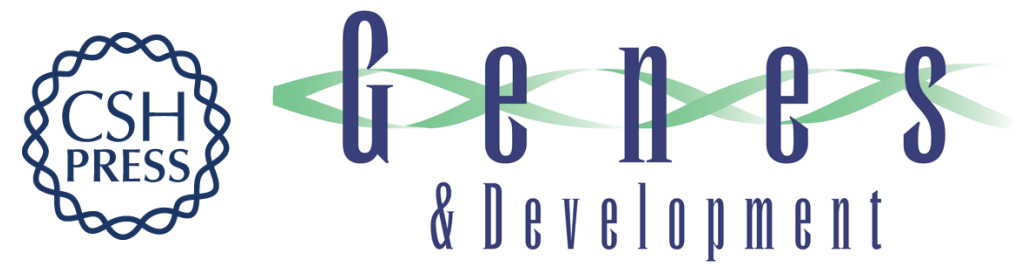

\section{Tissue-specific control of brain-enriched miR-7 biogenesis}

Nila Roy Choudhury, Flavia de Lima Alves, Luisa de Andrés-Aguayo, et al.

Genes Dev. 2013, 27:

Access the most recent version at doi:10.1101/gad.199190.112

Supplemental

Material

References This article cites 63 articles, 24 of which can be accessed free at: http://genesdev.cshlp.org/content/27/1/24.full.html\#ref-list-1

License Freely available online through the Genes \& Development Open Access option.

Email Alerting Receive free email alerts when new articles cite this article - sign up in the box at the top Service right corner of the article or click here.

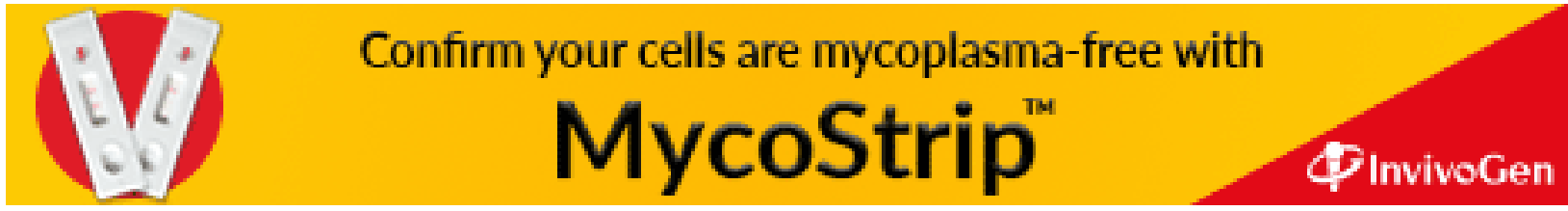

